\title{
Die Prämonstratenserabtei Steinfeld im 14. Jahrhundert.
}

Von

Theodor Paas.

\section{Abt Friedrieh (1303-1334).}

Nach der freiwilligen Amtsniederlegung Adolfs von Dollendor $f^{1}$ ) trat der Abt Friedrich, ein Sohn des Grafen Ludwig von Irnsberg und seiner Gemahlin Petronella von Jülicb, an seine stelle $\left.{ }^{2}\right)$. Er war nach dem Beispiele seiner Vorgänger mit Ausdauter und Erfolg bemüht, die gesunde wirtschaftliche Entwicklnng des Klosters, die seit dem Tage seiner Gründung nur einmal, um die Mitte des 13. Jahrhunderts, gehemmt worden war $^{3}$ ), in den rechten Bahnen weiterzuführen. Durch Schenkung und Erbschaft, durch Stiftungen, Pachtungen und Ankäufe gelang es ihm, dem Kloster neue wertvolle Vermögensobjekte zuzuführen.

Im Jahre 1306 erhielt er von dem Kölner Bürger Jobannes, einem Enkel der Frau Blume, und dessen Schwiegersohn Hermann

1) S. Annalen 95, S. 123.

2) S. die series praepositorum et abbatum Steinfeldensium im Düsseldorfer Staatsarchiv (Hand8chrift ohne Seitenzahl). Die von Aegidius Gelenius überlieferte Nachricht, der Abt Friedrich sei auch Erzbischof von Bremen gewesen, ist nicht zutreffend und wohl auf eine Verwechslung mit dem aus demselben Geschlechte der Grafen von Arnsberg stammenden Erzbischof Gottfried zurückzuführen, der im Jahre 1348 die Regierung der Erzdiözese Bremen-Hamburg übernahm. S. I. C. Hugo, Sacri et canonici ordinis Praemonstratensis annales. Tomus II, Nanceii 1736, col. 857. C. Eubel, Hierarchia catholica medii aevi. Monasterii I 2 1913), p. 146.

3) S. Annalen 95, S. 93. 
einen Erbzins von zwei Mark zum Geschenk, welcher auf einen Hause am Marktplatze in Zülpich lastete und von den Bewohnern des Hauses Jakob von Roitzheim und seiner Frau Benedicta entrichtet werden musste ${ }^{1}$ ).

Am 1. Februar 1311 schenkte der Abt selbst unter der Voraussetzung, dass die Schenkung von dem Generalabte Ada und dem Generalkapitel in Prémontré die nachgesuchte Bestäti. gung erhielt, seine Güter in Niederzier der Abtei zu dem Zwecke dass den Mitgliedern des Konventes aus ihren Erträgen eille Pitan\% gewährt werde ${ }^{2}$ ).

Die Kölner Bürger und Eheleute Peter und Bela Dorlant. welche in Zülpich ihren Wohnsitz hatten, schenkten am 4. Mai 132; einen Erbzins von zwei Mark, welcher aus dem Hause des Jobaln Bruse (Updercaminatin) in Zülpich zu erlegen war ${ }^{3}$ ), und der Edelherr Philipp IV. von Wildenburg überwies im Einverständnis mit seiner Gemahlin Johanna der Abtei im Jahre 1328 als frejer und unbelastetes Eigentum einen Acker in Wahlen bei Steinfeld".

Da die Abtei seit dem Jahre 1276 die päpstliche Vollmacht besass, alle beweglichen und unbeweglichen Güter, welche den Chor. herren und Konversen vor ihrem Eintritte ins Kloster auf Grund des Erbrechts zustanden, für sich zu erwerben und als Eigentum zu behalten ${ }^{5}$ ), hatte der Abt wiederholt Gelegenheit, für da: Kloster oder seine Mitglieder eine Erbschaft anzunehmen ${ }^{6}$ ). is

1) S. ebenda 24, S. $271 \mathrm{f}$. Mitteilungen aus dem Stadtarchiv von Köln, 5. Heft (Köln 1884), S. 4. Die Schenkungsurkunde wurde aus. gestellt in Gegenwart der Steinfelder Kanoniker Johann und Gumpert. der Pfarrer von St. Martin in Zülpich und Hochkirchen, sowie des Ordensbruders Hildebrand, welcher der Verwalter des Klosterhofes in Bessenich war.

2) S. Annalen 24, S. 275. Mitt. a. d. Stadtarchiv 5, S. 12.

3) S. Annalen 24, S. 280 f. Mitt. a. d. Stadtarchiv 5, S. 7.

4) S. J. F. Schannat-G. Bärsch, Eiflia illustrata I, 2 (1825) 691. In Jahre 1330 fiel auch die curtis Steinvelt cum omnibus suis attinentii: juxta domum Frederici Schegter in der Sporergasse zu Köln - ob durch Schenkung oder Kauf oder einen andern Rechtstitel, ist nich: ersichtlich - an das Kloster Steinfeld. S. H. Keussen, Topographie der Stadt Köln im Mittelalter I (Bonn 1910), 218b, 1- 4 .

5) S. Annalen 95, S. 110.

6) Aber noch öfter verzichtete er auf eine solche Erbschaft zu gunsten von weltlichen Angehörigen der erbberechtigten Steinfelder Chorherren und Brüder und zwar jedesmal, wenn die ungeschmälert 
Die Prämonstratenserabtei Steinfeld im 14. Jahrbundert.

erteilte er an 2. November 1312 dem Chorherrn Ruotger die Frlaulunis, itber die ihm beim Tode seines Vaters zugefallenen Erlbritter frei zu verfügen, und falls er sie verkaufte, den erziclten Gewinn zu seinem eigenen Gebrauche zu verwenden ${ }^{1}$ ).

Ebenso gestattete er am 3. April 1317 dem Laienbruder Throdorich Brincha, das in Köln dem Minoritenkonvent gegenillerliegende Haus, welches seine Schwester Drude, eine Begine, ihm hinterlassen hatte, für einen jährlichen, nach seinem Belieben verwendbaren Zins an den Kleriker Johannes und dessen Schwester (irete von Myrkenich zu vermieten ${ }^{2}$ ). Nur machte er dabei die Einschränkung, dass Theodorich, wofern das Kloster einmal infolwe driickender Not gezwungen sein sollte, Einkünfte zu verallssern, in diesem Falle den Zins dem Kloster zuwenden und

Frhaltung des Familienbesitzes aus irgendeinem Grunde wünsehenswert war. sei es, dass eine alte begüterte und einflussreiche Familie ihr Anselell behaupten wollte, sei es, dass mittellose Verwandte der Untersiitzung bedurften, oder wenn es sich um eine Stiftung ad pias causas himblelte. Darum gab er seine Zustimmung dazu, dass a) der Chorherr Heiurich, ein Sohn der Kölner Patrizier Johannes und Bliza Schönwetter, aII 19. Oktober 1310 alle ererbten Immobilien an seine Geschwister abtrat, is. die Originalurkunde Col. Nr.306 im KölnerStadtarchiv; vgl. Annalen 95, $\therefore$ 1‥- Anm. 1); b) der Chorhery Tilmann und der Laienbruder Wimar, di. Sühne des Ritters Th. von Lupenouwe und seiner Gemahlin Lucardis, lan in der Wolfsstrasse gelegene Haus zum Raben und die ganze Erb:hliaft, welche früher im Besitze des Wilhelm Mesischeym gewesen war, :III -24. Mai 1316 aus freien Stücken an die Eheleute Gobelinus und Bela ron Esch übertrugen (s. die Originalurkunde Col. Nr. 373 im Kölner itadtarchiv; Keussen a. a. O. I, S. 386a, 1-4); c) die Chorherren Ruotger uud Johannes, die Söhne der Kölner Eheleute Johannes und Grete, am 14. Februar 1323 ihren Anteil an einem jährlichen Zinse von 3 Mark, wrlcher auf dem Hause Denemark lastete, ihren Schwestern Bela, Grete unl . Meidis überliessen und am 25. August 1323 ihren Ansprüchen auf las Haus in der Engegasse (in stricto vicu) bei den Minderbrüdern entsapten, welches ihre Eltern zu einem habitaculum pauperum testamentarisch vermacht hatten (s. die Originalurkunde Col. Nr. $443 \mathrm{im}$ Kïlner Stadtarchiv; Keussen a. a. O. I, S. 281 a, 3. 4. 5. b, 4. 5; Originalurkunde Col. Nr. 435 im Kölner Stadtarchiv; Keussen a. a. O. I, S. 309b, 13. 14 [?]); d) der Prior Rutger am 17. September 1332 alle Rechte und Anspriiche auf die Güter preisgab, welche beim Tode seiner Schwester ('hristine, der Frau des Kölner Bürgers Johannes Moylre, geteilt wurden s. die Originalurkunde Col. Nr. 515 im Kölner Stadtarchiv).

1) S. die Originalurkunde Col. Nr. 334 im Kölner Stadtarchiv.

2) S. Keussen a. a. O. I, S. 306 a, 3 . 
ihn auch nach seinem Tode dem Kloster vermachen müsse, eine Verpflichtung, für welche er auf der anderen Seite einen rechtlichen Anspruch auf lebenslänglichen Unterhalt aus den Gïtern des Klosters erhielt. Von der erteilten Erlanbnis machte der Abt den Amtleuten der Kolumbapfarre in Köln, in welcher das in Rede stehende Haus gelegen war, zum Zweeke der notwendigen Ein. tragung in die Schreinsbücher urkundlich Mitteilung ${ }^{1}$ ).

Als die beiden aus Köln gebürtigen Steinfelder Chorherren Gottschalk de Asino und Erwin de Clocken gestorben waren, übertrug der Abt am 1. Oktaber 1328 seinem Kellermeister Johannes die Vollmacht, die Häuser und Hofstätten, welche das Kloster von ihnen geerbt hatte, zu dessen Gunsten zu verkaufell oder sonstwie zu veräussern ${ }^{2}$ ).

Am 23. April 1305 erbielt der Abt Friedrich von seinen Vorgänger im Amte, Adolf von Dollendorf, der wieder Prior in Meer geworden war $^{3}$ ), eine Summe von 50 Mark zur Stiftung eines Gedächtnisses in der Steinfelder Kirche, das fünfmal in Jahre für ihn selbst, seinen noch lebenden Bruder Heinrich und seinen verstorbenen Onkel Albert, Kanonikus von St. Viktor in Xanten und St. Cassius in Bonn, zu halten war ${ }^{4}$ ).

Von dem Domstifte zu Köln, als dessen Propst der Erzbischof Heinrich II. von Virneburg fungierte ${ }^{5}$ ), nahm die Abtei am 3. Mai 1306 den Hof Niederzier mit dem grossen und kleinen Zehnten, mit den zugebörigen Renten und Zinsen, Äckern und Wiesen und dem sogenannten Paffinvurst, aber mit Ausschluss der Vasallen, Ministerialen, Wachszinsigen und des Patronatsrechts über die dortige Pfarrkirche für einen jährlichen Zins von 90 Maltern Weizen und zwei fetten Ebern im Alter von drei Jahren, sowie eine Rekognition von 25 Mark beim jedesmaligen Amtsantritte

1) S. die Originalurkunde Col. 382 im Kölner Stadtarchiv.

2) S. die Originalurkunde Col. 479 im Kölner Stadtarchiv. In derselben ist die Lage der beiden Häuser nicht näher bezeichnet. Ein Bruder oder wenigstens Verwandter jenes verstorbenen Steinfelder Chorherrn, Gottschalk de Asino, war vermutlich Peter de Asino, der Kellermeister des Klosters Dünwald, welcher in einer Urkunde vom 11. November 1334 als Zeugre auftrat. S. Annalen 44, S. $81 \mathrm{f}$.

3) S. ebenda 95 , S. 123.

4) S. die series praep. et abb. Steinf.

5) Der Dompropst war eín Curiale, Bindus von Siena, der nie nach Deutschland kam. S. Kisky, Domkapitel der geistl. Kurfürsten (1906), S. 43 Nr. 31. 
eines neuen Propstes im Domstifte in Erbpacht'). Damit sie im Besitze der erworbenen Güter von niemandem belästigt werde, wies der Erzbischof den Ritter Arnold Spede, Vogt zu Niederzier, aill 15. des folgenden Monats an, sein Augenmerk auf die Abtei verichtet zu halten, und sie, wenn es nötig sein sollte, mit Hilfe des weltlichen Armes zu schützen ${ }^{2}$ ).

Von diesem Ritter Arnold Spede nahm die Abtei im Jahre 1309 einen bei Niederbolheim gelegenen Wald von $7 \frac{1}{2}$ Morgen, welcher jenem als Mannlehen von dem Herrn von Bergheim übertragen war, für einen jährlichen Zins von sieben Denaren und einew Obolus in Erbpacht ${ }^{3}$ ) und kaufte gleichzeitig (14. April 1309) ron ihm für einen Betrag von 144 Mark einundzwanzig ebenfalls bei Niederbolheim in der Pfarre Blatzheim gelegene Morgen Ackerland ${ }^{4}$ ).

Dazu erwarb sie am 5. Februar 1312 durch Kauf von Gottfried Spede, dem Sohne des inzwischen verstorbenen Ritters Irnold, den Hof in Mittelbolheim mit 70 Morgen Ackerland, Wiesen, Renten und Leuten für eine Summe von 500 Mark ${ }^{5}$ ), ferner am 22. Juli 1322 von den Eheleuten Heinrich und Mechtilde in Frauenberg bei Euskirchen für 16 Mark den Neubruchszelmten von den Feldern bei Call, auf welchen eine jährliche Rente von drei Maltern Hafer lastete, die Friedrich von Schleiden dem Reynard Engels aus Keldenich als erbliches Lehen ubertragen hatte. Aus diesem Grunde gab Friedrich zu dem Kaufvertrage scine Zustimmung nur mit dem Vorbehalte, dass die Erbrente von den jeweiligen rechtmässigen Inhabern ohne seine und seiner Erben ausdrückliche Erlaubnis nicht abgelöst werden dürfe ${ }^{6}$ ).

Ausserdem kaufte die Abtei am 1. Januar 1329 durch die Vermittlung des Steinfelder Pastors ${ }^{7}$ ) Gottfried von den Eheleuten

1) S. die Originalurkunde Nr. 35 im Düsseldorfer Staatsarchiv.

2) S. Annalen 24, S. 270. Mitt. a. d. Stadtarchiv 5, S. 4 f.

3) S. A. Fahne, Urkundenbuch des Geschlechts Spede jetzt Spee, 1. Lid., Köln 1874, S. 24.

4) S. ebenda S. 25.

5) S. ebenda S. 27.

6) S. Annalen 24, S. 278. Mitt. a. d. Stadtarchiv 5, S. 49.

7) Dass unter dem in der Urkunde erwähnten custos der mit der Abhaltung des Pfarrgottesdienstes und der Verwaltung der Pfarre betraute Chorherr zu verstehen ist, darüber s. H. Schäfer, Pfarrkirche und Stift in deutschen Mittelalter, Stuttgart 1903, S. $182 \mathrm{ff}$. 
Gobelin und Catharina Molrepesch in Wahlen (für eine nicht ge. nannte Summe Geldes) eine jährliche Rente von einem Malter Spelt und einem Malter Hafer, welche am 11. November in sorg. fältig gereinigtem Zustande zu liefern war, und erhielt von ihnen als Pfand ibr Haus in Wablen mit Hof, Garten und 30 Morgen Land 1). Von den Eheleuten Tilmann und Matbilde in Geyden. berg erwarb sie (justo venditionis titulo) am 3. Mai 1332 eine jährliche Rente von zwei Maltern Spelt und bekam von ilunen als Sicherheit ihr in Geydenberg gelegenes Haus mit Hof, Garten und sämtlichen Ländereien ${ }^{2}$ ). Durch Kaufakt vom 6. Dezember 1333, bei welchem sie durch ibren Pastor Gottfried und den Pastor Silkin von St. Martin in Zülpich vertreten wurde, übernabm sie von den Eheleuten Simon und Rigmodis die in Cluppylsayse (?) in der Gemeinde Breinig gelegenen Waldungen ${ }^{3}$ ).

Im Vergleich zu diesen bedeutenden Gütererwerbungen, welche Friedrich der Abtei zuführte, waren die Veränsserungen, die er an ibrem Besitztum vornahm, kaum nennenswert. Um der Kölner Bürgerin Christine, einer Schwester des verstorbenen Tuchhändlers Thomas, welcher die Abtei einen jäbrlichen Zins von zwei Mark schuldete, genügende Sicherheit zu schaffen, bevollmächtigte er am 15. Mai $1303^{4}$ ) seinen Kellermeister Conrad, ibr das in der Krebsgasse (kovergassen) in Köln gelegene, der Abtei gehörige Haus $^{5}$ ) vor den Amtleuten der Kolumbapfarre zu übertragen $\left.{ }^{6}\right)$.

Am 15. Juli 1327 vermietete er das in der Krebsgasse neben dem Brunnen liegende Haus ${ }^{7}$ ) an die Eheleute Heinrich den Viehhüter und Alveradis für einen jährlichen Zins von einer Mark,

1) S. Annalen 24, S. 281 f. Mitt. a. d. Stadtarchiv 5, S. 70.

2) S. Annalen 24, S. 282 f. Mitt. a. d. Stadtarchiv 6, S. 7.

3) S. Annalen 24, S. 283. Mitt. a. d. Stadtarchiv 6, S. 11.

4) Aus diesem Datum, welches in der Urkunde deutlich angegeben ist, geht zur Gewissheit hervor, dass die Abdankung seines Vorgängers Adolf von Dollendorf nicht in das Jahr 1304, sondern spätestens in den Anfang des Jahres 1303 fiel und seine Regierungszeit statt 6 nur 5 Jahre dauerte. Demgemäss sind die Zeitangaben oben, Annalen 95, S. 121 und 123 umzuändern.

5) Da dieses Haus wahrscheinlich das einzige war, welches die Abtei in der Krebsgasse besass (domum nostram sitam in Kovergassen), ist es wohl idéntisch mit dem gleich zu nennenden Hause in Kovergassen juxta puteum.

6) S. die Originalurkunde Col. 226 im Kölner Stadtarchiv.

7) S. Keussen a. a. O. I, S. 335 b, 1-4. 
welcher am Feste des hl. Martin an das Steinfelder Hospiz in Kïln zu entrichten war ${ }^{1}$ ). Dasselbe lag in der Engergassen gegeniiher der Seitenmauer des Hauses zum Löwen und war im Jahre 1286 von Albertus Scallo als Absteigequartier dem Kloster ges(henkt worden ${ }^{2}$ ).

Zu den Amtleuten der Kolumbapfarre schickte der Abt Friedrich am 25. März 1330 seinen Kellermeister Johannes mit dem Auftrage, die beiden in der Glockengasse gelegenen Steinfelder Häuser, welche von dem Magister Johannes Belle ${ }^{3}$ ) und Johames von Merzenich ${ }^{4}$ ) bewohnt waren, dem Petrus Ruysmunt als Sicherheit dafür zu geben, dass er zehn Mark - woher die Verpflichtung rührte und wie sie mit dem Kloster Steinfeld zusammenhing, ist in der Urkunde nicht angegeben - an die Eheleute von Keylse zahlen musste von dem Hause in der Sternenrasse, welches früher das Eigentum des Bäckers Burchard ${ }^{5}$ ) gewesen $\left.\operatorname{war}^{6}\right)$.

Da die Steinfelder Abtei ibre Güter im landwirtschaftlichen Eigenbetriebe hatte, ist bei dem immer mehr anwachsenden Besitz vorauszusetzen, dass sie im Anfange des 14. Jahrhunderts über zahllreiche geeignete Arbeitskräfte verfügte, sowohl Chorherren, die als Kellermeister an der Spitze der städtischen Höfe standen,

1) S. die Originalurkunde Col. 470 im Kölner Stadtarchiv.

2) S. Keussen a. a. O. I, S. 218a, 1-4. Wie die rheinischen Klöster des Zisterzienserordens Altenberg, Heisterbach und Kamp, so hatten auch die Steinfelder Prämonstratenser ein grosses Interesse daran, in Köln ein Absteigequartier zu besitzen, um hier in der Resideuz des Lirbischofs und im Mittelpunkt eines ausgedehnten Handels ihre reliriösen und wirtschaftlichen Interessen mit Nachdruck vertreten zu können. Vgl. H. Pauen, Die Klostergrundherrschaft Heisterbach, Münster i. W. 1913 , S. 2; 59 f. Das hier von den Zisterziensern Gesagte gilt auch von dén Prämonstratensern, da diese das Wirtschaftssystem jener nachahmten; s. Innalen 94 , S. $10 \mathrm{f}$.

3) S. Keussen a. a. O. I, S. 316 a, 10. 11.

4) S. ebenda S. $318 \mathrm{~b}, 3.4$.

5) S. ebenda S. $268 \mathrm{a}, 21.22$.

6) S. die Originalurkunde Col. 488 im Kölner Stadtarchiv. Uber zwei Verträge, welche die der Steinfelder Abtei gehörig’e Gemeinde Wehr und den dortigen Klosterhof betreffen, vom 7. Februar 1327 und 30. Mai 1330, s. Th. J. Lacomblet, Urkundenbuch für die Geschichte des Niederrheins, 3. Bd, Düsseldorf 1853, S. 187 Nr. 220 und die Originalurkunde Nir. 45 im Düsseldorfer Staatsarchiv. 
als auch Konversen, die als magistri curiae in Verbindung mit anderen Konversen und einer Schar von Tagelöhnern (mercenarii) die ländlichen Höfe bewirtschafteten ${ }^{1}$ ). Ü̉ber die Zusammensetzung des Konventes fehlen aus jener Zeit die Nachrichten gänzlich. Nur ist bekannt, dass der Erzbischof Heinrich, der durch eine Bulle des Papstes Clemens V. vom 5. Februar 1308 das Recht erhalten hatte, in jedes Männerkloster innerhalb der Kölner Kirchenprovinz je eine geeignete Person als Mönch oder Regularkanoniker einzuführen und in den Genuss der Präbenden zu setzen. vorausgesetzt, dass nicht ein anderer darauf Anspruch hatte\%, am 21. Juli desselben Jahres, indem er von diesem Rechte Ge. brauch machte, dem Dechanten des Ahrganes, dem Propste des Kassiusstiftes in Bonn, dem auch das Eifeldekanat mit Steinfeld unterstand ${ }^{3}$ ), den Befehl zur Ausführung zugehen liess, dass ein gewisser Hermann, ein Sohn des Ritters Sigfried von Hademal, ins Steinfelder Kloster als Ordensmann aufgenommen, mit dem Ordensgewande bekleidet, von den Gütern des Klosters unterhalten und liebevoll behandelt werde, genau so wie alle übrigen $K_{0 n}$. ventsmitglieder. Sofern jemand der Ausführung dieses Befehles Widerstand entgegensetzte, sollte der Dechant ihn zurechtweisen, und falls er innerhalb sechs Tagen nicht Folge leistete, mit dem Bann belegen ${ }^{4}$ ).

Umso besser sind wir unterrichtet über das religiös-kirchliche Leben in den Kapellen, welche zu der Pfarrei Steinfeld gehörten und von Steinfelder Chorherren bedient wurden. In den Kapellen zu Sistig und Call brach über die Zeit und die Feier des Gottesdienstes zwischen der Abtei und Friedrich III. von Schleiden ${ }^{5}$ ) ein Streit aus. Aber der Offizial der Kölner Kurie legte ihn durch die Vermittlung des Propstes zu Rees, Lutter von Maytlar, der zugleich Kanonikus an St. Gereon in Köln war ${ }^{6}$.

1) S. Pauen a. a. O.S. $78 \mathrm{f}$.

2) S. Lacomblet a. a. O. III, S. 37 Nr. 50, Anm. 1.

3) S. W. Fabricius, Erläuterungen zum geschichtlichen Atlas der Rheinprovinz, 5. Band, 1. Hälfte, Bonn 1909, S. $126 \mathrm{ff}$.

4) S. Annalen 24, $272 \mathrm{f}$. Mitt. a. d. Stadtarchiv 5, 6.

5) S. Schannat-Bärsch a. a. O. I, 2, S. 657, 1014 f. Er war ein Sohn jenes Conrad III., welcher im Jahre 1267 mit der Abtei Steinfeld in eine heftige Fehde geraten war. S. Annalen 95, S. $103 \mathrm{ff}$.

6) S. P. Joerres, Urkundenbuch des Stiftes St. Gereon zu Kölı. Bonn 1893, S. 244 Nr. 235; S. 254 Nr. 246. 
all1 23. September 1310 in der Weise bei, dass der Abt sich verpflichtete, vom 1. Fastensonntage bis zum Feste Allerheiligen in der Kapelle zu Sistig an jedem Sonntage und gewöhnlich auch am Nittwoch und Donnerstag, in der Kapelle zu Call an jedem sinutag und regelmässig am Freitag und Samstag durch einen steinfelder Chorherrn die hl. Messe lesen zu lassen, mit der nïheren Bestimmung, dass, wenn zwei Feiertage in der Woche gefeiert wurden, an diesen beiden Tagen die Messe gelesen wurde, Ind wenn ein Feiertag in die Woche fiel, die Messe an diesem Feiertage und einem anderen Wochentage stattfinde. Vom Allerheiligenfeste bis zum 1. Fastensonntage hingegen sollte in beiden Kapellen die hl. Messe an allen Sonn- und Feiertagen oder, wenn kein Feiertag einfiel, abgesehen vom Sonntage, in der Woche eimmal an einem geeigneten Tage gelesen werden, immer vorausgesetyt, dass der amtierende Geistliche nicht durch Krankheit oder einen anderen gerechten Grund verhindert war. Zugleich wurde dem Priester die Pflicht auferlegt, acht Tage vor Weihnachten mul 14 Tage vor Palmsonntag zeitig nach Sistig und Call zu kommen und nach der Messe bis zur Non zu warten, damit die Leute dort Gelegenheit fänden, ihre Beichte abzulegen. Wer bis zu diesem Termine nicht erschien, musste zur Mutterkirche nach steinfeld gehen ${ }^{1}$ ).

Der Kapelle zu Schleiden, welche im Jahre 1230 im Einrerständnis mit dem Steinfelder Abte erbaut und geweiht war $^{2}$ ), verlieh der Erzbischof Heinrich am 17. Mai 1317 das Recht, ein baptisterium zu errichten, da sich wegen der weiten Entfernungen teei der Taufe der Kinder in der Pfarrkirche zu Steinfeld zuweilen (iefahren und Unzuträglichkeiten einstellten, die beseitigt werden mussten. Dieses Privilegium knüpfte er an die Bedingung, dass der Mutterkirche in ihren Rechten, Zehnten und sonstigen Einkiuuften kein Eintrag geschah und der Abt und Konvent zu Steinfeld ihre Zustimmung dazu gaben. Sollte aber wirklich jemand sich unterstehen, gegen die Mutterkirche mit List oder Gewalt vorzugehen, ohne sich innerhalb Monatsfrist zu bessern, so ging dic Kapelle zu Schleiden des baptisterium verlustig und trat wieder in das frühere Verhältnis zur Mutterkirche ${ }^{3}$ ).

1) S. Annalen 24, S. 273 ff. Mitt. a. d. Stadtarchiv 5, S. 10.

2) S. Annalen 95 , S. $82 \mathrm{f}$.

3) S. Annalen 24, S. 276. Mitt. a. d. Stadtarchiv 5, S. 27. 
Diese Bewilligung einer Taufkapelle kann gewissermassen als der Abschluss und friedliche Ausgang einer Streitigkeit all. gesehen werden, welche zwischen Friedrich von Schleiden und dem Abte Friedrich von Steinfeld von neuem ausgebrochen war iiber den Gottesdienst in den Kapellen zu Schleiden, Sistig und Call, über die Benutzung der Wälder, den grossen und kleinen Zehnten, über gewisse Hoheitsrechte und eine Summe baren Geldes von 114 Mark $^{1}$ ). Schon am 23. Februar 1315 batten beide Parteien zur Schlichtung des Streites Sehiedsrichter ernannt, der Abt den Prior Adolf von Dollendorf in Reichenstein ${ }^{2}$ ) und dell Schatzmeister Gottfiried in Steinfeld, der Edelherr seinen Burg. mannen und Ritter Johannes de domo lapidea ${ }^{3}$ ) und den Vogt Reynard von Friesheim. Zum Vorsitzenden des Schiedsgerichts (tamquam superiorem arbitrum et totius arbitrii magistrum) be. stimmten beide Parteien den Magister Gerhard von Jülich ${ }^{4}$ ), Doktor des kanonischen Rechts und Komtur der Johanniterkommende॥ in Nideggen und Velden, und verpflichteten sich gegenseitig, die eine Partei der anderen eine Strafe von 100 Mark zu zablen, wenn sie den Schiedsspruch nicht annehmen wïrde, der innerhalb acht Tagen gefällt werden sollte ${ }^{5}$ ).

Nach fünf Tagen trat der Gerichtshof im Kloster Steinfeld zusammen und gab in Gegenwart des Priors Gottfried, des Sub. priors Adam, des Kellermeisters Heinrich, des Magisters und Kanonikus Wilhelm vom Marienstift in Aachen und des Kaplaus des Herm von Schleiden namens Georg, folgenden Schiedsspruch bekannt: Der Gottesdienst in der Kapelle zu Schleiden, deren

1) Die früheren Streitigkeiten des Klosters mit den Herren von Schleiden s. Annalen 95, S. 68 ff.; 79 ff.; 95 ff.; 103 ff. Auch mit dem Herrn Johann von Wildenburg, dem Vater des oben (S. 48) genannten Edelherrn Philipp IV., hatte der Abt Friedrich eine heftige Fehde auszukämpfen. Die Uxsache und der Verlauf derselben sind zwar nicht bekannt, aber in einer Urkunde vom Jahre 1310 gab Johann mit seiner Gemahlin Irmgardis seinem Bedauern über sein Vorgehen Ausdruck und leistete der Abtei Schadenersatz. S. Schannat-Bärsch a. a. O. I, 2, S. 690.

2) S. Annalen 95, S. 123.

3) Weiteres über diesen Ritter Johannes Steinhaus s. bei Schannat. Bärsch a. a. O. II, 2, S. $301 \mathrm{f}$.

4) S. Zeitschrift des Aachener Geschichtsvereins, 11 Bd., Aachen 1889, S. 147.

5) S. Steinfeld Akten 12a, S. 19 f. im Düsseldorfer Staatsarchiv 
Zurehörigkeit zur Pfarre Steinfeld ausdrücklich ausgesprochen wurle (appendicium), sollte von zwei Steinfelder Chorherren geInalten werden, welchen das Kloster Speise, Trank und Kleidung , 11 stellen hatte, während die übrigen Lebensmittel und Bedürfnisse alls den Oblationen und sonstigen freiwilligen Gaben gedeckt wurden. Zur Bequemlichkeit des Hern und der Leute von schleiden erhielt die Kapelle das Taufrecht, jedoch so, dass die sonstigen Rechte der Mutterkirche in keiner Weise verkiirzt wurden. Wenn einer von den beiden Priestern oder beide durch ungeziemenden Wandel Anstoss erregten, musste der Abt, oder wenn dieser auf Reisen war, der Prior auf Verlangen des Herrn ron schleiden einen oder $z$ wei andere geeignete Priester schicken, welche dem Herrn von Schleiden genehm und nicht anderweitig durch Gottesdienst in Steinfeld in Anspruch genommen waren.

In den Kapellen zu Sistig und Call, deren Zugehörigkeit zur Pfarre Steinfeld ebenfalls von neuem anerkannt wurde, sollte rou einem Steinfelder Chorberrn dreimal wöchentlich, nämlich in sistig Sonntags, Montags und Mittwochs, in Call Sonntags, Freitags umd Samstags Gottesdienst gehalten werden, mit der weiteren Massgabe, dass der amtierende Geistliche, wenn in der Woche Exerfuien oder Hochzeiten zu feiern waren, zu diesem Zwecke die übliche Messe las und ausserdem noch den dreimaligen Wochendienst hielt, vorausgesetzt, dass kein gerechter und wichtiger Hinderungsgrund vorlag.

Dem Abte wurde das Recht zuerkannt, nur aus dem Teile der in der Herrschaft Schleiden gelegenen Waldungen des Klosters Hol\% zu holen und zu veräussern, welcher innerhalb des Flusswerbietes der Olef und Urft gelegen war, und immer nur insoweit, als das Holz zum Brennmaterial in den Gebäuden und auf den Hlifen bestimmt war, es sei denn, dass ihm von dem Herrn von sichleiden und dessen Erben auf seine Bitten oder durch eine besundere Gunst oder je nach Bedarf ein weitergehendes Recht ausdriicklich eingeräumt war.

Wern aus den Wäldern des Herrn von Schleiden, die in der steinfelder Pfarre lagen, Neubruchsland gewonnen wurde, so komnte von diesem derjenige den Zehnten erheben, welcher ihn dem Rechte nach auf Grund der bisher zwischen dem Kloster und den Herren von Schleiden getroffenen Vereinbarungen erheben sollte. Die zur Kapelle Sistig gehörenden Leute mussten 
den Garbenzehnten und den gedroschenen Weizen, den sie in letzten Jahre vorenthalten hatten ${ }^{1}$ ), bei der nächsten Ernte in der Weise ersetzen, dass sie statt einer zwei Garben und das doppelte Quantum des Weizens ablieferten. Von den Früchten der Gemüse. gärten brauchte der Zehnte nicht entrichtet zu werden, wie es früher (1252) vereinbart war ${ }^{2}$ ). Zur Deckung ibrer Tiere durften die Leute der Sitte gemäss Stiere, Eber und Widder balten.

Der Herr von Schleiden hatte die Pflicht, auf seinem Hofe in Sistig unter den bisher üblichen Bedingungen und Umständen Recht zu sprechen ${ }^{3}$, ebenso wie der Abt von Steinfeld auf seinem Hofe in Marmagen. Die Abtei konnte den Wald Hetzelhoven, den Hof Kalberg und den Acker Mechtilhoven, drei Güter, welche sie schon seit 40 Jahren in Besitz hatte, ruhig solange weiter als ibr Eigentum ansehen und gebrauchen, bis der Herr von Schleiden, der behauptete, dass sie Lehngüter seien und zu seiner Herrschaft gehörten, dafür den strikten Beweis erbracht batte.

Bezüglich einer Summe von 114 Mark, welche dem Kloster Steinfeld durch Vermittlung des Herrn von Schleiden zugeflossen war, blieb die Frage, wer ihr rechtmässiger Eigentümer sei, unentschieden und dem Gewissen der Beteiligten überlassen, ob sie zurückerstattet werden müsse oder nicht. Jedenfalls durfte der Herr von Schleiden ihretwegen von dem Abte nicht belangt werdent).

Der durch diesen Schiedsspruch erzielte Friede war diesmal von langer Dauer und bahnte zwischen beiden Parteien ein freund. schaftliches Verbältnis an. Am 3. Februar 1320 verzichtete Friedrich mit seiner Gemahlin Johanna, um seine gute Gesinnung gegen das Kloster zu zeigen, urkundlich auf die genannten Güter Hetzelhoven, Kalberg und Mecbtilhoven und erkannte sie fortan als das unbestrittene Eigentum der Abtei genau in derselben Weise an, wie alle anderen in seiner Herrschaft Schleiden ge. legenen Klosterbesitzungen ${ }^{5}$ ).

Im folgenden Monate tubte der Edelherr Friedrich in Ver-

1) Dass Zehnthinterziehungen in der Streulage öfter vorkamen s. bei Pauen a. a. O. S. 42.

2) S. Annalen 95, S. 97.

3) S. ebenda, S. 104.

4) S. Steinfeld-Akten $12 \mathrm{a}$, S. $21 \mathrm{ff}$. im Düsseldorfer Staatsarchir

5) S. ebenda, S. $25 \mathrm{f}$. 
lindung mit dem Magister Gerhard von Jülich ${ }^{1}$ ) das Schiedsrichteramt in einer Streitigkeit aus, welche zwischen dem Abte diolf ron Dollendorf in Knechtsteden ${ }^{2}$ ) und dem Abte Friedrich in steinfeld ausgebrochen war wegen der von jenem beanspruchten, aler ron diesem seit einiger Zeit nicht ausbezablten Rente von Nein, Hafer und Geld ${ }^{3}$ ). Sie waren als Schiedsrichter erwählt rou dem Abte Adolf, der seine Sache selbst vertrat, und dem schatzmeister Gottfried und dem Kellermeister Johann Iswylre in Steinfeld, welche im Auftrage des in der Ferne weilenden thtes Friedrich handelten. Nach eingehender Untersuchung entschieden sie am 17. März 1320 in Gegenwart des Chorherrn Erwin und des Laienbruders Heinrich Noyrenberg aus Steinfeld, sowie des Kanonikus Thomas aus Knechtsteden, dass die beiden Beauftragten im Namen des Steinfelder Abtes binnen drei Wochen all den Abt Adolf drei Ohm Wein, 40 Malter Hafer und 20 Mark als Erbrente abliefern mussten und so in Zukunft regelmässig an den in Vertrage festgesetzten Terminen, ausserdem binnen drei Wochen noch zwei $0 \mathrm{hm}$ gewöhnlichen Weins und 60 Mark in Bar ${ }^{4}$ ).

Weiter erkiärte der Edelherr Friedrich mit seines Gemahlin Johanna am 13. Mai 1321, um Missverständnisse und Unklarheiten zu zerstreuen, durch welche so leicht wieder Zwistigkeiten zwischen ihm und der Abtei hervorgerufen werden konnten, dass der Neubruchszelıte in Busch und Feld innerhalb der ganzen Herrschaft Schleiden voll Rechts wegen der Abtei für immer zustehe, so dass weder er noch seine Erben einen Anspruch auf ihn geltend machen könnten ${ }^{5}$ ), und trat endlich am 19. Oktober 1322, von beiden Parteien anwruten, noch einmal als Schiedsrichter in einer Streitsache auf, welehe zwischen der Abtei und den Dörfern Harpersebeid, Bronsfelı, Schönseifen, Schleiden, sowie den übrigen rechts von der Olef" gelegenen, zu der Herrschaft Schleiden gehörigen Ortschaften wegen des Zehnten sich ausgebildet hatte. Er entschied dahin und der Abt Friedrich gab seine Zustimmung zu dem Entscheide - , dass die Bewohner der auf dem rechten Ufer der Olef liegenden

1) S. oben, S. 56 .

2) S. Annalen 95, S. 123.

3) S. ebenda, S. 114 .

4) S. die Originalurkunde Nr. 43 im Düsseldorfer Staatsarchiv.

5) S. Annalen 24, S. 277 f. Mitt. a. d. Stadtarchiv 5, S. 46. 
Ortschaften von allen Getreidearten den Zehnten zahlen müssten, nicht aber von Schweinen, Ziegen, Hühnern und Bienen ${ }^{1}$ ).

So erfreute sich die Abtei eines guten Einvernehmens mit ihrem mächtigen grundherrlichen Nachbar, dem Herrn von Schleiden. Indessen wurde ihre Ruhe bald von anderer Seite durch einen gewissen Gerhard von der Heyden gestört, welcher mit mehrere!! Helfershelfern in Bunde einen frevelhaften Angriff auf sie machte. Die Einzelheiten dieses gewalttätigen Vorgebens sind zwar nicht bekannt, aber der Steinfelder Kellermeister lud die Ehelente Clas und Jutta von Kelse, die er der Tat für mitschuldig hielt, vor das Schöffengericht in Köln nnd bat den Ritter Johann Mule und den Ritter Cone, Truchsess des Herrn von Bergheim, der Gerichts. verhandlung beizuwohnen. Hier stellten die Angeschuldigten nicht nur jede positive Mitwirkung zu der Tat entscbieden in Abrede, sondern sagten auch auf das Bestimmteste aus, dass dieselbe gan: ohne ibr Wissen geschehen sei und erklärten sich bereit, ihre Aussage eidlich zu erhärten. Darum musste sich der Kellermeister in Ermangelung anderer Indizien, die eine weitere gerichtliche Verfolgung hätten bewirken können, mit diesem Bescheide, dell die genannten Ritter ihm am 23. April 1330 überbrachten, z. frieden geben and die Sache niederschlagen ${ }^{2}$ ).

Während hier der gewünschte Ëfolg ausblieb, gelang es dem Steinfelder Kellermeister, in der Pfarre Hochkirchen, wo er gleicl. zeitig Pastor war ${ }^{3}$ ), eine strittige Angelegenheit siegreich durchzufechten. Die Pfarrangehörigen führten auf einer Synode, welche der Pastor Franko von Lechenich in seiner Eigenschaft als Dechant des Kapitels der Christianität Bergheim am 25. Februar 1320 in ihrem Pfarrbezirk abhielt, lebhaft Klage darüber, dass das Tor ihres Kirchhofes sich in schlechtem Zustande befinde, und fordertey von dem Kloster auf Grund einer rechtlichen Verpflichtung die not wendige Reparatur. Da aber der Pastor von Hochkirchen diese Pflicht entschieden in Abrede stellte - gemäss der Urkunde rom Jahre 1194 batte das Steinfelder Kloster nur dafür Sorge zu tragen. dass das Dach des Schiffes der Kirche stets in guterm Zustande gehalten wurde ${ }^{4}$ - - , beschlossen die Synodalmitglieder unter Zn-

1) S. Annalen 24, S. 279 f. Mitt. a. d. Stadtarchiv 5, S. 49.

2) S. die Originalurkunde Nr. 44 im Düsseldorfer Staatsarchiv.

3) S. Annalen 95, S. $122 \mathrm{f}$.

4) S. ebenda, S. 66 . 
stimmung beider Parteien, dass das Kloster frei ausgehen solle, weul zwei glaubwürdige Priester der Steinfelder Kirche unter Fiil erklären würden, dass jene Verpflichtnng nicht bestehe. Daher erschien am Passionssonntage desselben Jahres (16. Mälz) der hillermeister mit mebreren Priestern aus steinfeld, welche sich in Gegenwart des Dechanten, des Pfarrers Heimrich von Kelz und les Pfarrers Heinrich von Wissersheim sofort bereit zeigten, den rewitnschten Eid zu leisten. Aber zum Ergötzen der Erschienenen weigerten sich die Pfarrangehörigen, den Eid anzunehmen und die - ache weiter zu verfolgen. Infolgedessen erklärte der Dechant, dis: das Kloster mit der Ablebnung der Forderung im Rechte sei ${ }^{1}$ ).

Die Beziehungen, welche zwischen der Abtei Steinfeld und ilıren Tochterklöstern bestanden, hielt der Abt Friedrich sorgfältig. :ufrecht. Für das Kloster Dünwald gab er wiederholt seine Zustimmung, wenn es sich um Pacht- und Renten-, Kauf- und schenkungsverträge handelte, die erst durch seine Mitwirkung liecbutskraft erlangen konnten, odel er nahm für das Kloster eine stiftung an und bestätigte und besiegelte sie, um sie vor Anfechtung sicherzustellen ${ }^{2}$ ). In dem Kloster Meer verlieh er einer schenkung ${ }^{3}$ ) und einem Pachtvertrage ${ }^{4}$ ) seine Genehmigung. Auf Ninsch der Nonnen richtete er an den apostolischen Stubl die Bitte, er möge ihrem Kloster, in welchem die Zahl der Schwestern friiher durch Konventsbeschluss und mit päpstlicher Genehmigung auf 40 festgesetzt worden war ${ }^{5}$ ), in Zukunft gestatten, dass es bei der

1) S. Annalen 24, S. 276 f. Mitt. a. d Stadtarchiv 5, S. 40.

2) So am 29. November 1304; 17. März, 11. September und 9. De. \#mber 1309; 1315 (ohne Angabe des Tages und Monats); 13. Juli und 10. 0ktober 1325; 11. November 1330. S. das Pergament-Kartular aus dem Finde des 15. Jahrhunderts im Stadtarchiv zu Köln (seine BeschreiIn11y in der Zeitschrift des Bergischen Geschichtsvereins, herausgegeben ion W. Crecelius und W. Harless, 20. Bd., Bonn 1885, S. $53 \mathrm{f}$. und in I'n Annalen 44, S. 5): Q. 1 fol. 55; J. 6 fol. 36; B. 3 fol. 5; D. 16 fol. 22 b; J. 10 fol. 36 b; K. 5 fol. 39 . Zeitschr. des Berg. Geschichtsvereins 22, $\therefore 109 \mathrm{ff}$. H. Mosler, Urkundenbuch der Abtei Altenberg, I. Band, Bonn 1912 , S. 479.

3) 6. Januar 1315; s. die Originalurkunde Nr. 41 im Düsseldorfer Sthatsarchiv.

4) 2. Februar 1317; s. das Pergament-Kartular a. a. O. Nr. 8 fol. 47. 7.itschr. des Berg. Geschichtsvereins 22, S. 113.

5) S. Annalen 95, S. 85, Anm. 4. 
Aufnahme neuer Mitglieder über diese Zahl unter Umständen auch hinausgehe. Nachdem der Papst Johannes XXII. diese Bitte unter der Voraussetzung gewährt hatte, dass das Kloster die nötigen Mittel besitze, um alle seine Mitg]jeder unterhalten zu können. schlich sich in der Folgezeit in das Kloster die Unsitte ein, dass bei der Einkleidung von Nonnen ein unsinniger und übertriebener Aufwand gemacht wurde. Infolgedessen sab sich der Erzbischof Walram von Jülich, der Nachfolger Heinrichs II., genötigt, an deu Abt Friedrich von Steinfeld, welcher die Pflicht der Oberleitung. Beaufsichtigung und Zurechtweisung über das Kloster auszulüluell hatte, die bestimmte Weisung zu richten, dass er gegen diese $\mathrm{C}_{\mathrm{n}}$. sitte mit aller Entschiedenheit einschreite. Der Abt kam den erzbischöflichen Befehle am 24. Juni 1333 gewissenhaft nacb und beschränkte die Kosten der Einkleidung für alle neu einzutretenden Mitglieder obne Unterschied des Standes auf 40 Mark, eine Snmme. welche die Eltern oder Verwandten an die Klosterkasse abzuliefern hatten ${ }^{2}$ ).

Auch die böhmischen Klöster, welche der Leitung Steinfelds unterstanden, nahmen die Sorge des Abtes Friedrich in Ansprucl. Im Beginne des Jahres 1306 trat er eine Reise nach Böhmen an und bielt am 17. März in dem Stifte Selau, welches im Jahre 1144 von Steinfeld aus gegründet war $^{3}$ ), ein Ordenskapitel für die böhmischen Klöster ab, an welchem ausser ihm, dem Abte Tilmann von Selau und dem Abte Christian von Hamborn, welcher ihn uach Böbmen begleitet hatte, acht Äbte und ein Propst teilnahmen. Unter anderem handelte es sich darum, das Dorf Branitz, welches in der Nähe des mährischen Prämonstratenserinnenklosters Kanitz gelegen war und dem Stifte Selau als Eigentum gehörte, samt Hof, Mühle, Waldungen, Wiesen, Weiden, Äckern und allen Rechten für immer dem Konvente für die Kranken und zu eiwer Pitanz für die Mitglieder in Erbpacht zu geben. Diese Übertragung, welche der Abt von Selau auf Bitten seines Priors Johannes, des Snbpriors Hermann und des ganzen Stiftskapitels vollzog, bestätigte

1) Im päpstlichen Auftrage machte der Kardinalbischof von Albano, Gaucelinus Joannis Deuza, am 11. November 1330 hiervon dem Erzbischofe Heinrich von Köin urkundlich Mitteilung. S. die Original. urkunde Nr. 46 im Düsseldorfer Staatsarchiv.

2) S. die Orginalurkunde Nr. 47 im Düsseldorfer Staatsarchiv.

3) S. Annalen 93 , S. 40 ff. 
der Abt Friedrich von Steinfeld, der in Verbindung mit dem Abte Throdorich von Strahow von dem Generalabte Adam und dem (ieueralkapitel in Prémontré hierzu besonders bevollmächtigt war, und bedrohte die Zuwiderhandelnden mit kirchlichen Strafen ${ }^{1}$ ),

In die Reihe der von Steinfeld abhängigen Klöster trat wilhrend der Regierung des Abtes Friedrich als neves Glied das l'rimonstratenserinnenkloster Ellen bei Arnoldsweiler im Kreise Diiren, welches ursprünglich eine Tochtergründung der Abtei huechtsteden war. Die Mitglieder desselben hatten schon seit langer Zeit sich sittlich verirrt und vom Prämonstratenserorden rainzlich losgesagt, waren aber inzwischen zur Einsicht gekommen und wollten nun auf den rechten Weg zurückkehren. Da der Abt Nlatthias von Knechtsteden glaubte, wegen der weiten Entfernung und aus Mangel an geeigneten geistlichen Kräften sich des Klosters Eilleu nicht wirksam annehmen zu können, richtete er am 28. September 1308 an den Generalabt Adam in Prémontré die Bitte, ibn von der Leitung dieses Klosters zu entbinden und mit dersellen den Abt von Steinfeld zu betrauen, der sie mit Rücksicht auf die grosse Zahl der ihm zur Verfügung stehenden Chorberren ${ }^{2}$ ) lesser und leichter ausüben könne. Indem das Generalkapitel unter dem Vorsitze des Generalabtes den Bitten des Knechtstedener tbtes in Anerkennung der vorgebrachten Gründe Rechnung trug, ihergab es noch in demselben Jahre die Leitung des Klosters Ellen dem Abte von Steinfeld mit der bestimmten Weisung, dieser uclugewonnenen Prämonstratenserstiftung dasselbe väterliche Interesse und Woblwollen zu widmen wie der Steinfelder Niederlassung; etwaige widerstrebende oder aufrührerische Elemente durch kirchliche Zensuren zum Schweigen zu bringen, und wenn es nötig sein sollte, auch die Hilfe des brachium saeculare anzurufen ${ }^{3}$ ).

1) S. Zeitschr. des Aachener Geschichtsvereins 33, S. $288 \mathrm{f}$.

2) Das oben (S. 53) durch Schlussfolgerung gewonnene Resultat, luss der Steinfelder Konvent im Beginne des 14. Jahrhunderts stark besetzt war, wird hier urkundlich bestätigt.

3) S. L. C. Hugo, Probationes tomi primi monasteriologiae Praemonstratensis (Appendix zu Hugos Annales), col. 544 sq. Von dem Abte Friedrich berichtet Hugo ausserdem (Annales II, col. 857): Controversias "um capitulo $\mathrm{C}$ ol on i e $\mathrm{n}$ i super decimis in Ellen amicabiliter composuit anno 1310, während die series praepositorum et abbatum Stein. feldensium (im Düsseldorfer Staatsarchiv) von demselben Abte sagt: duno 1310 cum Cardonensi capitulo amicabiliter composuit con- 


\section{Abt Marsilius (1334--1356).}

Als der Abt Friedrich nach einer langen, reich gesegneten Regierungstätigkeit - der Überlieferung gemäss - im Jahre 1334 das Zeitliche gesegnet hatte, wählte der Steinfelder Konvent $z^{\prime \prime}$ seinem Nachfolger den Chorberrn Marsilius, der in einzelnen Hand. schriften aucb Silkinus oder Tzilkinus genannt wird ${ }^{1}$ ). Zu welcher Zeit der neu gewählte Abt im Laufe des Jahres 1334 den Stull] bestieg, lässt sich urkundlich nicht feststellen, obwohl aus diesen. Jahre zwei Nachrichten vorliegen, welche das Steinfelder Kloster und seinen Abt betreffen. Eine Urkunde vom 25. Mai 1334, in welcher die Eheleute Peter und Gertrud Kelner nnter anderen namhaften Vermächtnissen auch die Steinfelder Abtei mit einem Weinberge bei der Ortschaft Indirberre (?) testamentarisch be. dachten, nennt nicht den Namen des regierenden Steinfelder Abtes? und die andere Angabe, Marsilius habe zur Abstellung des im Kloster Meer eingeschlichenen Misshrauches, dass einzelne Nonne॥ mehrere Pfründen besassen, die weitere Verleibung von Pfründen an Personen, welche sich schon im Genusse einer solchen befanden, im Jabre 1334 unter der Strafe der Exkommunikation verboten. entbehrt des Datums, an welchem Tage und in welchem Monate er dieses Verbot erliess ${ }^{3}$ ).

Unter ihm kam der wirtschaftliche Aufschwung, den die Abtei bis dahin fast ununterbrochen genommen hatte, zum Stillstand. Der materielle Besitz erfuhr im Vergleich $z u$ den bedeutenden Er. werbungen seiner Vorgänger nur einen ganz geringen Zuwachs. Abgesehen davon, dass die Abtei im Jahre 1349 einen Hof in Langendorf bei Zülpich ankaufte ${ }^{4}$, erhielt sie durch ein Vermächt-

troversiam super decimis in Ell entz. Die letztere Lesart ist wahr. scheinlich die richtige und bezieht sich nicht auf den eben genannten Ort Ellen bei Arnoldsweiler, sondern auf die Ortschaft Ellenz an der Mosel, in welcher die Steinfelder Abtei Weinberge besass und wegen de; Zehnten schon wiederholt mit dem Kapitel des Kastorstiftes in Carden in Streit geraten war. S. Annalen 93, S. 28. 94, S. 8 f. 95, S. 42 Anm. 1.

1) S. die series praep. et abb. Steinf. Farragines Gelenii XXI. p. 146 (Handschrift auf dem Stadtarchiv zu Köln).

2) S. J. Krudewig, Ubersicht über den Inhalt der kleineren Archirr der Rheinprovinz. 3. Band, Bonn 1909, S. $101 \mathrm{f}$.

3) S. die series praep. et abb. Steinf. Hugo, Annales II, col. $83^{\circ}$. A) S shands 
nis des Pfarrers Heinrich von Dottel einen jährlichen Zins von vi( Naltern Weizen zu einer in Messen, Vigilien, Kommendationen, l'silmen und Gebeten bestehenden Stiftung, welche nach seinem T'ude für ilın und seine Angebörigen in der Steinfelder Kirche zu erfiillen war. Am 25. Mai 1349 nahm Marsilius mit dem Prior Johtumes und dem Subprior Reinard die Stiftung an und verItlichtete sich, für ilhre genane Erledigung Sorge zu tragen, während :uit scinen Wunsch der Abt Conrad von Knechtsteden und der Prolst Gottschalk vou Wenau, die Visitatoren der westfälischen Zirkiaric, welcher die Abtei Steinfeld im Jahre 1320 bei der Eintriluug. des gesamiten Prämonstratenserordensgebietes in (29) Zirkiric! rom Generalkapitel \%ugewiesen worden war ${ }^{1}$ ), die Urkunde hrivenclten ${ }^{2}$.

Dagegen war es ein grosser Gewinn bzw. eine bedeutende Firjarnis an Auslagen, dass die Abtei am 4. August 1340 von dem Markgrafen Wilhelm V. von Jülich ${ }^{3}$ ), der auch den Kreuziltar in der Steinfelder Kirche neben der Begräbnisstätte der illte gestiftet und dotiert hatte, die Zollfreiheit für alle durch die Markgrafschaft Jülich hindurehgehenden Güter erlangte ${ }^{4}$ ); pine Vergïnstigung, welche den Besitzungen der Abtei in Niederi.jer und Bessenich, in Zülpich, Hochkirchen, Nieder-, Mittel- und Wherbolheim sebr zustatten kam.

F'ür den äussern Bestand der Abtei traf der Bruder des Markgrafen, Walram von Jülich, der im Jahre 1332 den erzlisishöflichen Stubl in Köln bestiegen hatte ${ }^{5}$ ), eine wichtige Vermilunug, indem er am 29. Oktober 1345 die über die Gründung

1) A circatore id est a visitatore etymon trahit circaria. Ille enim, 'ulus providentiae regni aut provinciae alicujus monasteria subsunt et 'ircumeundo visitat, ut disciplinam vel contineat florentem vel lapsam in-tauret, ille circator nuncupatur. S. die praefatio zu Hugos Annales I.

2) S. die Originalurkunde Nr. 54 im Düsseldorfer Staatsarchiv. I siner Topographie der Stadt Köln im Mittelalter (I, S. 218 b, 5. 6) erwihnt Keussen aus dem Jahre 1346 noch: domus in arto vico juxta Inmum Steynvelt. $O b$ aber dieses Steinfelder Haus erst unter der liegierung des Abtes Marsilius erworben wurde oder schon früher im Hisit\% des Klosters war, wird sich schwerlich entscheiden lassen.

3) S. Zeitschrift des Aachener Geschichtsvereins 13, S. $123 \mathrm{ff}$.

4) S. die Kopie (des 18. Jahrhunderts) Nr. 51 im Düsseldorfer ilatsarchiv.

5) S. Zeitschrift des Aachener Geschichtsvereins 12, S. 207. 
des Prämonstratenserklosters Steinfeld ausgefertigte Urkurde seines Vorgängers Friedrich I. vom Jahre 11211), welche ibm der Abt Marsilius im Original und gut erbaltenen Zustande vorgelegt hatte, ausdrücklich bestätigte und damit das ursprüngliche Verbot. die kanonische Lebensweise der Steinfelder Chorherren jemals zu ändern, von neuem aussprach ${ }^{2}$ ).

Von demselben Erzbischof Walram erhielt Marsilius in Jahre 1347 für immer die Befugnis, einen geeigneten Geistlichen zur Abhaltung des Gottesdienstes an die Kapelle zu Ebren des allerheiligsten Sakramentes za berufen, welche der Dechant des Marienstiftes in Aachen, Hermann Blanckart, unterstittat ru mehreren frommen Gläubigen, in der Martinspfarre in Zülpich mit seiner Zustimmung.s) erbaut and mit den erforderlichen Einkïnftell ausgestattet hatte ${ }^{4}$ ).

Am 1. März 1350 nabm Marsilius das Benediktinerkloster Brauweiler in die Gebetsverbrüderung auf, indem er dessen dh Friedrich aus dem Geschlechte der Grafen von Seynheym nud alle Mitglieder des Konventes sämtlicher hl. Messen, Psalmeu.

1) S. Annalen 93, S. 18 ff.

2) S. die Originalurkunde im Stadtarchiv zu Köln. Mitt. a. ¿. Stadtarchiv 6, S. 54. In dem in der Urkunde enthaltenen Transsum finden sich einige von dem durch Lacomblet a. a. O. I, S. $191 \mathrm{f} . \mathrm{Nr} .20$ ? gebotenen Texte abweichende Lesarten, durch welche der Sinn aller. dings nicht wesentlich geändert wird. Abgesehen von den Verbesst. rungen, welche Ennen (in den Annalen 23, S. 152) schon vorgenommel. hat, ist noch zu erwähnen, dass in der 9. Zeile von oben zwischen ,il. comitatu ipsius" und "a progenitoribus" die Worte einzuschieben sind: prefati fidelis mei cum omnibus pertinentiis suis, quod erat juris ipsill: Ferner ist in dem Transsumt bezüglich der Frist, welche den Kloster. vögten zur Sinnesänderung eingeräumt war, falls sie ibre Ptlicht ver letzt hatten, bestimmt gesagt: Quodsi ... per inducias ter IV ebdomada. appellatus non fuerit correctus, afferatur (statt auferatur) ei advocaci: während bei Lacomblet diese Frist unbestimmt gelassen ist: Si . . p pe: inducias hebdomadum appellatus usw.

3) Diese Zustimmung war erforderlich, weil die Steinfelder Abte über die Martinspfarre das Patronatsrecht besass. S. Annalen 95, S.70.117

4) S. die series praep. et abb. Steinf. Hugo, Annales II, col. $85{ }^{\circ}$ 370. Hier ist statt des Erzbischofs Walram ( $\uparrow 14$. August 1349) irrtümlic dessen Nachfolger Wilhelm genannt. Der Ort, an welchem die (nic! mehr vorhandene) Sakramentskapelle stand, heisst in Zülpich heute nor der Gottesberg. S. J. G. Broix, Erinnerungen an das alte berülm! Tolbiacum, die jetzige Stadt Zülpich, Neuss 1842, S. 103. 
Hymmen, Vigilien, Empfehlungen, Gebete, Fürsprachen und sonstigen gnten Werke des Steinfelder Konventes teilhaftig machte und in seinem Kalender anordnete, dass für sie jährlich in der Fastenzeit eine feierliche hl. Messe in der in seinem Orden üblichen IV (ise gelesen werde ${ }^{1}$ ).

Das ruhige, religiös-aszetische Leben im Kloster, welches die steinfelder Chorherren auf Grund ihrer Ordensregel eifrig zu pflegen hatten, wurde unter der Regierung des Abtes Marsilius durch die alte Feindseligkeit der Herren von Schleiden, die mit crncuter Wucht losbrach, schwer gestört und nachbaltig geschädigt. IIährend früher einzelne Glieder dieser Familie Ansprüche auf (irundbesitz, Zehnten und nutzbare Rechte vor Gericht gegen das kloster geltend gemacht batten ${ }^{2}$ ), ging Johann $\mathrm{I}^{3}$ ), ein Enkel jenes Friedrich, mit welchem der Abt Friedrich in Streit geraten war ${ }^{-1}$ ), kurz nachdem er seinem (1345) verstorbenen Vater Conrad IV. ${ }^{5}$ ) in der Regierung gefolgt war, mit roher Gewalt z.tum offenen Angriff gegen das Kloster vor. Infolgedessen musste Varsilius gemäss den kireblichen Bestimmungen, welche der Erzhischof Heinrich auf den Provinzialsynoden von 1310 und 1322 erlassen hatte, den Frevler bei dem erzbischöflichen Offizial zur luzcige bringen ${ }^{6}$ ).

Demselben legte er Beschwerde fübrend dar, dass Johann mit seinen Knechten und Dienern den in der Pfarre Sistig gelegrenen Klosterhof Reipach überfallen, das Kloster der Pferde, llchsen und Kühe, der Saaten, der Zehnterträge, die noch anf dem Felde standen, des gesanten Heuvorrates, aller Utensilien und Yobilien, die auf dem Hofe, den Äckern und Feldern anzutreffen

1) S. Annalen 18, S. 113. Aus dem Steinfelder Konvent ist sonst weiter nichts bekannt, als dass ein gewisser Thomas Knur, welcher ihm jure servilis conditionis angebörte, von dem Abte Marsilius am 14. Septrmber 1352 aus der Hörigkeit und dem Klosterverbande entlassen wurde, da er in einen strengern Orden einzutreten wünschte. S. die Oriwiulurkunde Nr. 55 im Düsseldorfer Staatsarchiv.

2) S. Annalen 95, S. 68 ff. 79 ff. 95 ff. 103 ff.

3) S. Schannat-Bärsch a. a. O. I, 2, S. $658 \mathrm{ff} .1015 \mathrm{f}$.

4) S. oben S. $56 \mathrm{ff}$.

5) S. Schannat-Bärsch a. a. O. I, 2, S. $657 \mathrm{f} .1015 \mathrm{f}$.

6) S. Schwamborn a. a. O. S. 54 ff. 59. Hauck a. a. O. V, 1, S. 139 f. (4). $149 \mathrm{f}$. Über das Amt und die Stellung der bischöflichen Offiziale $\therefore$ ebenda S. $157 \mathrm{ff}$. 
waren, beraubt und die geraubten Sachen nach seiner Burg Schleiden gebracht hatte; die Leute des Klosters hatte er von dem Hofe verjagt und den Hof selbst mit Beschlag belegt, die Wälder, die dem Kloster gehörten, verwüstet and in ihnen $\mathrm{H}_{0} \mathrm{O}_{2}$ gefällt zu seinem eigenen Bedarf. Damit noch nicht zufrieden. hatte er den Abt und die Chorherren an ihrem Leib und Eigen. tum bedroht und ihnen die kirchliche Freiheit entzogen. $D_{a s}$ alles war so offenkundig und in der Steinfelder Pfarre und der weiteren Nachbarschaft so allgemein bekannt, dass der Abt sich bereit erklärte, die Richtigkeit seiner Aussagen eidlich zu er. härten.

Anf diese schweren Auschuldigungen hin lud der Offizial den Herrn von Schleiden auf den 30. Oktober 1346 vor sein Gericht und verurteilte ihn in contumaciam. Sodann befahl er nach vorangegangener Eidesleistung des Abtes den Pfarrern in Steinfeld, Münstereifel, Reifferscheid, Schleiden, Holzheim, Buir Olef, Dottel, Keldenich, Marmagen, Weyer, Nettersheim, Conzen, Simmerath, Zülpich, Erp und Müddersheim, sowie dem gesamteı Klerus der Stadt und Diözese Köln, unter Strafe der suspensiı ab officio und der Exkommunikation, die über sie verhängt sein würde, wenn sie nicht innerbalb drei Tagen seinen Befehl ans. geführt bätten, dass sie gegen den Angeklagten die Vorschriften der Provinzialstatuten genau beobachteten.

Gemäss der für Räuber, Plünderer und Diebe kirchlicher und klösterlicher Güter festgesetzten Strafe verfiel jeder Ort der Stadt und Diözese Köln, an welchen der Herr von Schleiden und seine Helfershelfer kamen oder ihren Raub brachten, ipso fact" dem Interdikt mit völliger Einstellung des Gottesdienstes, und zwar auf zwei Monate, wenn die Verbrecher oder die geraubtel: Gegenstände länger als drei Tagen an dem betreffenden Orte blieben. Die Frevler selbst und alle die, welche sie aufnabmen und unterstützten, sowie die Käufer der geraubten Gegenstände waren mit Nennung des Namens, wofern sie namentlicb bekamut waren, oder sonst allgemein zur Restitution und Sühne aufzufordern und als sakrilegisch und exkommuniziert öffentlich bekannt $z$ machen, wenn sie in drei Tagen dieser Aufforderung nicht nact. kamen. Verharrten sie aber 14 Tage in der Exkommunikation. so wurden sie in allen Pfarr- und Konventualkirchen des Dekanates. in welchem die Herrschaft Schleiden gelegen war und die Frevler 
(iil Domizil hatten, unter Glockengeläute und bei ausgelöschten hirzen an allen Sonn- und Feiertagen, bis eine volle Sühne geleistet war, als Exkommunizierte offentlich bekannt gegeben. Finllich erhielt der Herr von Schleiden die Weisung, dem Abte und den Chorherren, weil er sie an Leib und Eigentum bedrobt battc, innerhalb sieben Tagen Sicherheit zu verschaffen; im Nicigerungsfalle batte er dieselbe Strafe der öffentlich ausgesprochenen Exkommunikation zu gewärtigen. In der Durchfillırung dieser kirchlichen Bestimmungen verlangte der Offizial rinl den Pfarrern, dass der eine nicht auf den anderen wartete, sondern jeder selbständig vorging und ihm unverzüglich mitteilte, wils er in der Angelegenheit getan habe ${ }^{1}$ ).

Welchen unmittelbaren Erfolg diese scharfe Massnahme ter Kurie erzielte, ist urkundlich nicht festzustellen. Dass sie : llsweführt wurde, beweist ein Schreiben vom 13. März 1347, in welchem der Pastor von Wichterich bei Zülpich dem Offizial meldete, dass er den in seiner Pfarre ansässigen Ritter Johannes Busch aufgefordert habe, innerbalb drei Tagen der Abtei Steinfeld die geraubten Sachen zurückzuerstatten, die er, wie allgemein hek:unnt war, in seiner Wohnung aufbewahrte, widrigenfalls er dell in den Provinzialstatuten vorgesehenen und vom Offizialat woch besonders zu verbängenden Strafen verfalle ${ }^{2}$ ).

S'chliesslich griff der Erzbischof Walram selbst in das gerichtliche Verfahren ein und ernannte zu Schiedsrichtern den l'ropst an St. Patroklus in Soest, Wilhelm von Gennep ${ }^{3}$ ), den Herm Johann von Reifferscheid ${ }^{4}$ ), Herrn Conrad von Dyck $^{5}$ ), lie Ritter Reinbard von Schönau ${ }^{6}$ ) und Heinrich von Sinzigi"). I)iesc gaben am 17. September 1347 in Köln als Schiedsspruch

1) S. Steinfeld-Akten 12 a, S. 28 ff. im Düsseldorfer Staatsarchiv.

2) S. ebenda S. 31 .

3) Den späteren Erzbischuf von Köln (1349-1362). S. W. Pelster, Stand und Herkunft der Bischöfe der Kölner Kirchenprovinz im Mittelalter, Weimar 1909, S. 16.

4) S. Schannat - Bärsch a. a. O. I, 2, S. 623 f. 922. Zeitschr. des Aachener Geschichtsvereins 1, S. $198 \mathrm{f}$.

5) S. Annalen 55, S. 81 Nr. 61, S. 197 Anm. 1. $\therefore$ is.

6) S. Zeitschr. des Aachener Geschichtsvereins 8, S. 212. Annalen 15,

7) S. Zeitschrift des Bergischen Geschichtsvereins 12, S. 184. Annaien 17 , S. 222. 
bekannt, dass 1 . beide Parteien alle feindselige Gesinnung gegen. einander ablegen und insbesondere die Steinfelder Chorherren denen Verzeihung gewähren sollten, von welchen die Klosterbrüder geschlagen und verwundet worden waren, sowie den Helfershelfern des Herrn von Schleiden, seinem .Bruder Conrad von Scbleiden 1 und Gottfried von Neuenahr ${ }^{2}$ ). 2. Die neuen Forderungen, welche Johann gegen das Kloster erhoben hatte, wurden abgelehnt, näm. lich die Anlage eines Badehauses in dem Kotzenbache, jedes Jahr die Lieferung eines Windseiles zur Befestigung und Sicherheit der Zelte, die jährliche Lieferung eines Pelzrockes und je eines Paares Schuhe und Handschuhe an die Wächter des Herm vou Schleiden, die Aufzucht von zwei Hunden auf dem Hofe Reipacb für den Herrn selbst und die Anlage einer Strasse durch den Hof. Nur wurde dem Kloster auferlegt, zur Verfügung für die Leute des Herrn von Schleiden ein Fohlen zu halten. 3. Die Schöffen des Herrn in Sistig waren verpflichtet, jährlich alı Feste des hl. Andreas auf dem Hofe Reipach Recht zu spreche॥ und erhielten dafür von dem Kloster eine Beköstigung, wie sic den Klosterbriidern gegeben wurde, und wie der Graf Wilhelm von Jülich und der Herr Philipp von Wildenburg es im Jahre $12 \pi$ bereits festgesetzt hatten ${ }^{3}$ ). 4 . Der Herr von Schleiden, welcher auf alle seine obengenannten Ansprüche ausdrïcklich verzichtete, wurde wegen. seiner gewalttätigen Angriffe auf die Abtei und der Schäden, dir er ihr verursacht hatte, weiter nicht behelligt und freigesprochen. 5. Zum Ersatz für den angerichteten Schaden und zur Bekrältitigung des gütlichen Übereinkommens, das von beiden Seiten an. erkannt wurde, blieb die Abtei zwei Jahre lang, rom Tage der Ausstellung der Urkunde ab gerechnet, von allen Forderunger. and Diensten völlig frei. Nach Ablauf dieser Frist traten beidr Parteien wieder in ibre früheren Rechte ein, so wie sie urknnilich festgelegt waren ${ }^{4}$ ).

Aber noch vor Ablauf derselben - am 13. Mai 1349 -.- ver. längerte Johann mit seiner Gemahlin Elisabeth von Virnebur: diesen Sühnevertrag aus freien Stücken auf zehn Jahre, um da

1) S. Schannat-Bärsch a. a. O. I, 2, S. 658.

2) S. ebenda S. 912.

3) S. Annalen 95, S. $104 \mathrm{f}$.

4) S. Steinfeld-Akten 12 a, S. 31 ff. im Düsseldorfer Staatsarchi 
gute nachbarliche Verhältnis weiter bestehen zu lassen. Erst wenn diese Zeit verstrichen war, erbielten beide Parteien ihre alten rerbrieften Rechte zurück ${ }^{1}$ ).

Eine andere strittige Angelegenheit kam vor das erzbischöfliche Gericht in Köln, als der Verwalter des Steinfelder Klosters, (t) to ron Alen, am 23. April 1350 vor dem Offizial den Matthias roll Pintzbeim beschuldigte, dass er den grossen Zehnten von acht Morgen Land bei Dorweiler in der Pfarre Hochkirchen in dem laufenden Jahre nicht bezahlt habe, obwohl sämtliche grosse Zehnten in dieser Pfarre dem Kloster anerkanntermassen rechtlich zustïnden. Auf Befragen gab der Beschuldigte zu Protokoll, dass nach seiner Ansicht jene acht Morgen von dem Zehnten wirklich frei grewesen seien und es auch noch seien, jedoch wolle er es weren einer so geringfügigen Sache nicht auf eine gerichtliche kntscheidung ankommen lassen. Darum begab er sich aller seiner wirklichen oder vermeintlichen Rechte und überwies den Zehnten :llls freien Stücken für immer dem Kloster. Der Verwalter Otto unul der Kaplan des Abtes, Kanonikus Wilbelm in Steinfeld, wivker ihn nach Köln zum Gerichte begleitet hatte, nahmen zwar ten Verzicht und die Übertragung an, erklärten aber ausdrücklich, Nass sie sich hierin von der Auffassung leiten liessen, nicht Matthias, sontern das Kloster habe den rechtlicben Anspruch auf den $\%$ Mnten gehabt, damit nicht der Anschein erweckt werde, als ob liier dem Kloster eine besondere Wobltat erwiesen sei ${ }^{2}$ ).

Ausser der Steinfelder Abtei, seinem eigentlichen Wirkungskreise, widmete der Abt Marsilius auch den 'Tochterklöstern seine Aufmerksamkeit und Sorge. Dem Kloster Dünwald gab er seine Znstimmung zn mehreren Schenkungs- und Kanfverträgen und verlich ihnen zur Erlangung der Rechtskraft seine Bestätigung ${ }^{3}$ ). Carchdem er sich damit einverstanden erklärt hatte, dass der Graf . Mlolf VI. von Berg't) und seine Gemahlin Agnes an dem Blasius-

1) S. die Originalurkunde Nr. 53 im Düsseldorfer Staatsarchiv.

2) S. Annalen 24 , S. 288 f. Mitt. a. d. Stadtarchiv 6, S. 70.

3) So an 14. August 1337; 20. Dezember 1343; 2. Januar 1345; 1 November 1348 ; 13. Dezember 1353 ; 1. August 1356. S. Pergamentkartular a. a. O. J 7 fol. 36 ; K 6 fol. $39 ; \mathrm{K} 10$ fol. $40 ; \mathrm{K} 9$ fol. $39 \mathrm{~b}$; l. $i$ fol. $42 \mathrm{~b}$; H 13 fol. 33 b. Zeitschr. des Berg. Geschichtsvereins 22, (.) $123 \mathrm{ff}$.

4) S. ebenda 3, S. $231 \mathrm{f}$. 
altare in der Pfarrkirche zu Dünwald eine tägliche heilige Hesse für die Seelenrube der Waffengefährten stifteten, die in den Kampfe zwischen dem Bischof Engelbert von Lüttich, dem $V_{\text {er. }}$ bündeten des Grafen, und den aufrührerischen Bürgeru der Bischofs. stadt gefallen waren, erhielt er am 16. April 1347 von dem $\mathrm{E}_{1 \%}$. bischof Walram die Vollmacht, jedesmal den von dem Grafen und dessen Rechtsnachfolgern für dieses beneficium präsentierten Weltgeistlichen zu investieren und zurechtzuweisen, falls er clie eiıgegangenen Verpflichtungen nicht beobachtete, ferner sämtliche Oblationen, welche auf dem genannten Altare von den Gläubigen geopfert wurden, für das Mutterkloster Steinfeld zu beziehen (cui ecclesia parochialis in Dunwalt praedicta annexa est, ut dicitur. et unita) ${ }^{1}$ ).

Im besondern Auftrage des Generalabtes Johannes und les: Generalkapitels von Prémontré unternahm Marsilius im Jahre 1336 eine Reise nach Böhmen, um das Kloster Strabow in Prag? welches einer völligen wirtschaftlichen Zerrüttung anheimgefalleı! war $^{3}$ ), einer gründlichen Visitation zu unterziehen. Nacliden ef sich mit den Äbten von Mülhausen und Klosterbruck, sowie dem Propste von Doxan ${ }^{4}$ ) ins Einvernebmen gesetzt batte, traf er folgende Anordnungen: der Abt Theodorich II. von Strabow durfte sich um die zeitlichen Angelegenheiten des Stiftes nicht mehr bekümmern, zu seinem persönlichen Dienste nur eineı Kaplan und zwei Reitknechte halten und an niemanden, gleich. viel welchen Standes, Einladungen zu Gastmahlen ergehen lassell. Wenn Gäste sich zufällig einstellten, musste er sie anf die herrschende Not binweisen und ihnen aus dem Wege gehen; er sollte sich möglichst oft von der Abtei fernhalten und die Grangien

1) S. Hugo, Probationes I, col. 540 sq. Annalen 44, S. 62.

2 S. ebenda 93 , S. $34 \mathrm{ff}$.

3) Auch andere Klöster des Prämonstratenserordens waren ul: jene Zeit in drückende Not geraten. Denn der Propst Hermann vo: Cappenberg untersagte am 18. Februar 1347 im Auftrage des Genera: abtes Johannes und des Generalkapitels den Vorstehern der westfälísch": Klöster, innerhalb zwei Jahren einen neuen Chorherrn aufzumehmen. d: der Orden wegen eingetretener Verarmung vieler Klöster genötigt î seine Mitglieder von einem $\mathrm{Kloster}$ in das andere zu versetzen. S. d: Originalurkunde $\mathrm{Nr} .52$ im Düsseldorfer Staatsarchiv.

4) S. Annalen 93, S. $39 \mathrm{f}$. 
und freien Güter aufsuchen, um auf diese Weise Kosten und Auslitren zu sparen.

Die Verwaltung des Stiftes übernahm ein Prokurator, der (l'n) Abte und seinen Dienern die nötigen Kleider, das erforderliche Reitzeug und die Mittel zu bescheidenen Auslagen verschlatfte, alle fälligen Zinsen an Geld und sonstigen Gütern, überh:ult alle Einkünfte einzog und zur Tilgung der Schulden verwilldte. Uber seine Amtstätigkeit hatte er genau Buch zu führen und zweimal im Jahre dem Abte, dem Prior und Subprior unter Ilinzazielıng einiger älteren Mitglieder des Konventes Rechenseltatt zu geben.

War der Abt im Kloster anwesend, so speiste er aus Sparsamkeitsriicksichten mit dem Prokurator an demselben Tische. stitl', der Prokurator, oder war er durch langwierige Krankheit all der Ansubung seines Amtes gehindert, so musste Theodorich die Ïbte von Mülhausen und Klosterbruck, sowie den Propst von boxal zusammenberufen und nacb ihrem Rate einen neuen Verwalter einsetzen. Diesen Anordnungen, welche der Abt Marsilins aIII 27 . März 1336 urkundlich festgelegt, unterwarf sich Theodurich durch feierliches Gelöbnis und musste sich ausserdem gefallen lassen, dass er im Übertretungsfalle abgesetzt und alle seine lintertanen vom Geborsam entbunden wurden ${ }^{1}$ ).

ob dieser Fall wirklich eintrat oder ob Theodorich, von hummer uiber sein Missgeschick niedergebengt, sein Amt freiwillig niederlegte oder durch Tod abberufen wurde, ist unbekannt. Jedenfalls schied er im Laufe des Jahres 1337 aus seiner Stellung und erhielt durch rechtmässige Wabl am 30. Oktober einen Nachfulger in dem Chorherrn Hildeger, dem bisherigen Kellermeister de: Stiftes. Der Abt Marsilius von Steinfeld bestätigte die Wahl ${ }^{2}$ ),

1) S. die Originalurkunde $\mathrm{Nr} .48$ im Düsseldorfer Staatsarchiv. line Kopie derselben findet sich in der series praep. et abb. Steinf.

2) S. Hug*o, Annales II, col. 956. Die (hier gewähite) Ausdruckswise: Theodericus II d e si it anno 1337 legt den Gedanken nahe, dass Throdorich nicht bis zu seinem Tode im Amte geblieben ist. Wenn A. Frind (Die Kirchengeschichte Böhmens im allgemeinen, 2. Band, P'ruy 1866, S. 192) berichtet, im Jahre 133i sei der Abt Tylmann von strahow wegen schlechter Vermögensverwaltung abgesetzt worden, so liegt hier wohl ein Irrtum im Namen vor, Tylmann statt Theodorich, ta diesem im Jahre 1336 durch Marsilius die Verwaltung des Stiftes mitzogen wurde. 
nachdem der Prior Heinrich und der Subprior Jakob in Strahow ihn am 8. November brieflich darum gebeten hatten, mit der Be. gründung, dass Hildeger ein rechtschaffener und wissenschaftlich gebildeter Mann sei, der in geistlichen und zeitlichen Dingen reiche Erfahrung besitze und von dem man vertrauensvoll er. warten könne, dass er die grossen Schäden der Abtei abstellen werde $^{1}$ ).

\section{Abt Winrich Rumsthöttel (1356-1362).}

DurcL die Wabl des Steinfelder Konvents gelangte nach dem Tode des Abtes Marsilius im Jabre 1356 der Chorherr Wilhelm Rumschöttel, ein Herr aus edlem Geschlechte ${ }^{2}$ ), welcher früher Prior in Dünwald gewesen war $^{3}$ ), in den Besitz der höchsten Würde und Gewalt in Steinfeld. Mit ihm brach für die Abtei eine traurige Zeit an. War schon unter seinem Vorgänger die wirtschaftliche gedeihliche Entwicklung fast ganz ins Stocken geraten ${ }^{4}$ ), so trat in der zweiten Hälfte des 14. Jahrbunderts ein wirtschaftlicher Niedergang ein, welcher die Abtei in ihrem kräftigen, lebensvollen Bestande nicht nur ernstlich gefährdete, sondern sogar gänzlich zugrunde zu richten drohte.

Da dieselbe (gravi inopia compellente) bei mehreren Gläubigen eine Summe von $500 \mathrm{M}$. aufgenommen hatte, für die sie jährlich 40 M. Zinsen zahlen musste ${ }^{5}$ ), stellte ibr der Abt Winrich am 29. Mai 1358 aus seinen Mitteln $550 \mathrm{M}$. zur Verfügung, nm die Schuld einzulösen. Dafür überwies ihm der Konvent für die Zeit seines Lebens, gleichviel in welcher Stellung er sich befand, einen jährlichen Zins von 20 Goldgulden, die er aus dem Steinfelder

1) S. die Originalurkunde Nr. 49 im Düsseldorfer Staatsarchiv.

2) S. Hugo, Annales II, col. 857. Series praep. et abb. Steinf. Eï Glied dieser Familie, N. Rumschöttel, war um das Jahr 1300 Amtman! zu Caster und 1306 Droste zu Grevenbroich gewesen. S. Zeitschr. des Aachener Geschichtsvereins 12, S. 198 u. 22.

3) Als soleher ist er urkundlich nachweisbar seit dem 13. De zember 1353. S. Zeitschr. des Bergischen Geschichtsvereins 22, S. 130 Nr. 185. Annalen 44, S. 109.

4) S. oben S. 64 .

5) Úber die Höhe des Zinsfusses im Mittelalter s. M. Hoffmanı. Der Geldhandel der deutschen Juden während des Mittelalters bis zum Jahre 1350, Leipzig 1910, S. $70 \mathrm{ff}$. 
H:lus in $\mathrm{K} \ddot{\ln }{ }^{1}$ ) bezog, und $21 \mathrm{M}$., die aus seinem Hause in Andernitch $\%$ entrichten waren ${ }^{2}$ ).

Am 16. März 1359 vermachte der Steinfelder Kanonikus und Pfarrer zu Brachelen ${ }^{3}$ ), Hermann von Bonn, durch Testament, III welchem er seine Verwandten und Freunde bedachte, der thtei einen Weinberg zu Lengsdorf im Landkreise Bonn und eille grosse Zabl von Geschenken an Kleidungsstücken, Gefässen, Biicthern und anderen Gegenständen ${ }^{4}$ ). Dagegen verzichtete der steinfelder Chorherr Johannes mit Zustimmung des Abtes am - Oktober 1360 zugunsten seiner Scbwester Nese und deren (iemahls Heinrich von Bonn ${ }^{5}$ ) auf einen Erbzins von 12 M., welcher ilm beim Tode seiner Eltern Johannes und Blytza Wysse aus cinem Hause in der Schildergasse in Köln nahe bei dem Kloster der Kreuzberren zugefallen war $\left.^{6}\right)$.

Cnter dem Abte Winrich stand der Steinfelder Kirche als P'astor der Chorherr Wilbelm von Gressenich vor, welcher im Jatre 1358 eine vita B. Hermanni Joseph und eine vita S. Potentini et sociorum necnon officium de eis schrieb $^{7}$ ). Im Jahre 1359

1) Da die Lage dieses Hauses in der Urkunde nicht näher brejchnet ist, wird sich schwerlich feststellen lassen, welches Haus wemeint ist, da die Steinfelder Abtei in Köln mebrere Häuser besass. S. Keussen a. a. O. I, S. $190 \mathrm{a}, 13 ; 203$ b, $8 ; 218 \mathrm{a}, 1-4$. b, 5-7; $290 \mathrm{~b}, 3$; 4 4i) h l.

2) S. die Originalurkunde Nr. 56 im Düsseldorfer Staatsarchiv. Auf Wunsch des Konventes hängte der Prämonstratenserabt Amandus ron Sayn an die Urkunde, welche der Abt Winrich in Verbindung mit r.inem Prior Jobannes und Subprior Bartholomaeus über den gechloussenen Vertrag ausgestellt hatte, sein Siegel.

3) Die Beziehungen der Prämonstratenser zu der Pfarre Brachelen latierten aus der Mitte des 13. Jahrhunderts. Nachdem der Herr lleinrich zu Heinsberg und seine Gemahlin Agnes im Jahre 1245 das l'atrouatsrecht über die Pfarre dem Prämonstratenserinnenstift Heinsb) übertragen hatten, inkorporierte sie der Erzbischof Engelbert II. im ,Jahre 1263 dem Stifte. S. Knipping, Reg. der Kölner Erzb. III IIr. ㄴ.273 u. Zeitschr. des Aachener Geschichtsvereins 1, S. $251 \mathrm{f}$.

4) S. die Originalurkunde Nr. 57 im Düsseldorfer Stantsarchiv.

5) Die Besitzungen, welche Heinrich von Bonn in Köln hatte, $\therefore$ Keussen a. a. O. I, S. 124 a. b, S. $191 \mathrm{a}, 6-8$.

f) S. die Originalurkunde Col. Nr: 679 im Kölner Stadtarchiv.

7) S. Hugo, Annales II, col: 857 sq. F. Timmermans, Vie du bienheureux Herman Joseph, Lille-Paris 1899, p. 254 sq. L. Goovaerts, Ecri- 
bestätigte Winrich drei Kaufverträge, welche Conrad, der Prior des Klosters Dünwald, im Auftrage seines Konvents abgeschlosseu hatte ${ }^{1}$ ), und legte in Laufe des Jahres $1362^{2}$ ) sein Amt als Abt freiwillig nieder, um in die sorgenfreiere Stellung eines einfachen Ordensmannes zurïckzukehren; er lebte noch im Jahre 13783\%.

\section{Abt Matthias von Fisehenich (1362-1366).}

Der Nachfolger des Abtes Winrich, Matthias von Fischenich, stammte aus ritterlichem Geschlechte. Die einzige aus seiner Regierungszeit vorliegende Urkunde, ausgefertigt am 25. April 1363, gibt über eine Stiftung Auskunft, welche Agnes, die Witwe des Ritters Johann Kunninxs von Lendersdorf im Kreise Düren. in der Abteikirche zu Steinfeld errichtete, indem sie für ibre ver. storbenen Verwandten vier Jahrgedächtnisse, bestehend in Messell. Vigilien und Kommendationen in der in Steinfeld üblichen Weise halten liess und dafür eine Rente von zwei Maltern Spelt von ihrem 30 Morgen grossen Gute in Marmagen anssetzte ${ }^{4}$ ). Da der Abt sich nicht stark genug fühlte, die eingerissene wirtschaftlicbe Zerrüttung der Abtei aufzubalten. trat er nach vierjähriger Amtsführung, gleich seinem Vorgänger, von seinem Posten zuriick und übernahm die Leitung der Pfarre Fritzdorf ${ }^{5}$ ), über welche die Abtei seit dem Jahre 1292 das Patronatsrecht besass "). Zu seinem Nachfolger erhielt er den

vains, artistes et savants de l'ordre de Prémontré, Tome II, Bruxelles 1902, p. 353.

1) 19. März; ¿6. November; 14. Dezember. S. das Pergament-Kar tular a. a. O. J 1. fol. $35 ; \mathrm{K} 3$ fol. $38 \mathrm{~b} ; \mathrm{H} 12$. fol. $33 \mathrm{~b}$. Zeitschrift de Bergischen Geschichtsvereins 22, S. $131 \mathrm{f}$.

2) Ob er oder sein Nachfolger am 5. August 1362 von dem Propste zu Münstermaifeld, Heinrich von Sponheim, die Zusicherung erhielt, dass die Abtei wegen der zwischen dem Propste und dem Erzbischof Wilhelı von Köln bestehenden Fehde in ihrem Gute in Wehr nicht gepfändet werden könne und einen vollen Ersatz für den ihr bereits verursachten Schaden erhalten werde, lässt sich nicht ermitteln. S. die Originalurkunde Nr. 58 im Düsseldorfer Staatsarchiv.

3) S. Hugo, Annales II, col. 857. Series praep. et abb. Steinf.

4) S. Annalen 24, S. 292 f. Mitt. a. d. Stadtarchiv 7, S. 35.

5) S. Hugo, Annales II, col. 858 .

6) S. Annalen 95, S. 115. 


\section{Abt Conrad (1366-1369).}

Bei seinem Regierungsantritte war nach Hugo ${ }^{1}$ ) die Summe ler bei den Juden und Lombarden aufgehäuften Schulden der Ihtci anf über 12000 Goldschilde gestiegen, während sie sich nach ruer Angabe in der series praep. et abb. Steinf. auf 10000 Grollyulden belief. Un die Schulden su decken und die Gläubiger al befriedigen, blieb dem Abte nichts anderes übrig, als einen grussen Teil der Klostergüter zu veräussern und zu verpfänden; aul diese Weise gingen der Abtei viele Besitzungen verloren, von denen metrere 200 Jahre und noch länger ihr als gesicherte Einnilumequellen gedient hatten.

Gemïss einer summarischen Aufzeichnung in der series praep. 't abb. Steinf. verkaufte der Abt Conrad die Ortschaft Franken mit den Weinbergen, dem Zehnten und dem Patronatsrechte ${ }^{2}$, den Ort Kirchesch (?) mit der Hälfte des bei Kerpen gelegenen Figrentums, den Zehnten in Dreis bei Rheinbach ${ }^{3}$ ), die Höfe in hely im Kreise Düren, in Bachem und Kürrighoven im Landkreise Bumn, den Hof Oberbolheim mit der zugehörigen Mühle ${ }^{4}$ ) und deml Zehnten in Ollesheim, den Hof in Lüssem im Kreise Euskirchen, den Zehnten in Vochem im Landkreise Köln, die Wein lurrge in Röstorf und Blittersdorf (Rhöndorf ${ }^{5}$ ) und Plittersdorf?), eill llaus in Bonn und andere Güter. $\mathrm{Er}$ verpfändete den Hof Bessenich ${ }^{6}$ ) auf neun Jahre für 1800 M., den Hof in Hausweiler

1) S. Annales II, col. 858.

2) Eine spezielle Urkunde vom 29. August 1369 (irrtïmlich ist das Jatir 1319 genannt) meldet, dass er diese Besitzung Franken mit Zusinumung seiner beiden Amtsvorgänger Winrich Rumschöttel und Matthias von Fischenich, welche den Titel Unteräbte führten, sowie :imtlicher Steinfelder Chorherren, welche meistens Pfarrer waren und Wren Zahl sich auf 45 belief, an den Ritter Rolmann von Ahrenthal und seine Gemahlin Christine für eine Summe von 1500 Mark verkaufte.

$\therefore$ Boos a. a. O. 3, S. 53; 6, S. 41. Vgl. Annalen 95́, S. 64.113.

3) S. ebenda S. 116.

4) S. ebenda S. 64. 67. 112. $\therefore$ is

5) Die Besitzungen der Steinfelder Abtei in Rhöndorf s. ebenda

6) S. Annalen 93, S. 32.95, S. 64. 
(im Kreise St. Wendel?), den Hof Seheidtweiler ${ }^{1}$ ) bei Jakobwiilles. heim, den Hof in Wöstweiler (? quae nune sylva prope Ellen), die Höfe an der Mosel in Ellenz ${ }^{2}$ ), Ediger, Crör ${ }^{3}$, den Hof in Hochkirchen mit dem zugehörigen Zehnten ${ }^{4}$ ), den Wald in Dütt. ling ${ }^{5}$ ), die Guter in Wehr. ${ }^{6}$ ), den Hof in Ahrweiler ${ }^{7}$ ) und den Zehnten in Fritzdorf ${ }^{8}$;, die Güter in Bangen (Bengen?) und andere Liegenschaften ${ }^{9}$ ).

Um das Mass des Unglücks vollzumachen, kam noch der Übelstand hinzu, dass die Äcker, welche in der Nähe Steinfelds lagen, sowie die Höfe Königsfeld ${ }^{10}$ ), Reipach ${ }^{12}$ ) und Steinberg bei Wehr wegen der Armut und Not der Landlente unbebaut liegeu bleiben mussten ${ }^{12}$ ). Unter so trostlosen Umständen konnte sich der Abt Conrad nicht entschliessen, noch länger im Amte zu bleiben: er folgte dem Beispiele seiner beiden Vorgänger und legte im Jahre 1369 die schwere Abtswürde nieder ${ }^{13}$ ).

1) S. ebenda S. $114 \mathrm{f}$.

2) Am 30. September 1366 erklärte Hille von Dunebach urkundlich. dass sie von der Abtei Steinfeld auf Lebenszeit den Hof in Ellenz mit Weingarten und allem Zubehör für den dritten Teil des jährlichen Weinertrages in Pacht genommen habe. S. die Originalurkunde Nr. $61 \mathrm{im}$ Düsseldorfer Staatsarchiv. Hier kann also von einer Verpfändung im eigentlichen Sinne des Wortes nicht die Rede sein.

3) Utber die Weinberge der Abtei in Ediger und Cröv s. An. nalen 95 , S. 64 .

4) S. ebenda S. 65. 70, $122 \mathrm{f}$.

5) S. ebenda S. 67.

6) S. Annalen 93, S. $48 ; 95$, S. 83 f. 100.

7) S. ebenda S. 66. $77 \mathrm{ff}$.

8) S. ebenda S. 115.

9) S. die series praep. et abb. Steinf.

10) S. Annalen 95, S. $92 \mathrm{f}$.

11) S. ebenda S. $103 \mathrm{ff}$.

12) S. die series praep. et abb. Steinf. Dieselbe traurige Erscheinung wird auch aus anderen Gegenden Deutschlands in den Jahren 1372. 1375 und 1380 berichtet and zwar als eine Folge des schwarzen Todss und anderer Pestausbrüche. S. Hoeniger a. a. O. S. $87 \mathrm{f}$. Lechner a. ^. (). S. 72. 74. Die jammervolle Lage der Abtei schildert der Verfasser in allegorischer Weise mit den Worten: Hoc tempore Deus ... percussil petram Steinfeldensem et fluxerunt aquae et torrentes inundaverunt: p 77 ... et ita obruerant petram Steinfeldensem, ut vix apex ejusdem appareret.

13) S. Hugo, Annal es II, col. 858. 


\section{Abt Gerhard von Höningen (1369-1380).}

Anch unter dem neuerwählten Abte trat in den misslichen finalıiellen Verhältnissen der Abtei kein Umschwung zum Bessern cill. Den Verkauf der grossen Besitzung in Franken, welchen sin Vorgänger kurz vor seinem Rücktritt abgeschlossen batte, hesträtigte er am 12. Dezember 1374, nachdem er mehrere Male zII diesem Zwecke im Steinfelder Kloster eingehende Kapitelsberatungen gepflogen und die Vollmacht des Erzbischofs Friedrich nud die Zustimmung des Kölner Domkapitels erhalten hatte. Demgemäss übertrug er, um einen Teil der Schulden, die sich :llf mehr als 8000 Goldgulden beliefen, decken zu können, dem Kitter Rolmann von Abrenthal und seiner Gemahlin Christine ${ }^{3}$; wo certa pecuniarum quantitate et summa (inter nos) concordata ${ }^{2}$ ) allc beweglichen und unbeweglichen Güter der Abtei in dem Kirchspiel Franken mit dem Patronatsrecht über die Pfarrkirche unil dem grossen und kleinen Zehnten von Getreide, Wein und simutlichen Tieren, ferner mit den Höfen, Häusern, Äckern, Weinhergen, Wäldern, Weiden, Wiesen, Weidenpflanzungen (salicetis), Zinsen, Renten, sonstigen Einkünften, Kurmeden, Rechten und der loben und niedern Gerichtsbarkeit ${ }^{3}$ ).

Die Güter in Fritzdorf, Benghoven und Kürrighoven, welche tem Dechanten Hupert Molghin an dem St. Cassiusstift in Bonn früher (pro nonnullis magnis pecuniarum summis) verpfändet waren, mahm der ehemalige Abt von Steinfele, Winrich Rumschöttel ${ }^{4}$ ), au 12. Juni 1378 auf Lebenszeit für einen jährlichen Zins von iv Goldgulden in Pacht, um sie für das Kloster wiederzugewinnen, mämlich den Hof in Fritzdorf mit 60 Morgen Ackerland, fünf Morren Wiesen und 40 Morgen Wald samt den Leuten und

1) S. Zeitschr. des Aachener Geschichtsvereins 11, S. 12 f. Keussen a. a. (). I, S. 163 a, 1.

2) 1500 Mark. S. oben S. 77 Anm. 2.

3) S. die Kopie (des 18. Jahrhunderts) Nr. 65 im Düsseldorfer siatsarchiv.

4) Er stand mit den beiden anderen von ihrem Amte zurückgetretenen Then, Matthias von Fischenich und Conrad, dem Abte Gerhard zur Seite, III in wichtigen Angelegenheiten ihn zu beraten und zu unterstützen. Mle vier kamen darin überein, die Klostergüter in Breisig (Briske) arkaufen. S. die series praep. et abb. Steinf. 
Kurmedalen, Zinsen und Renten, dem Hofgerichte und anderent Rechten, in Benghoven acht Morgen Ackerland und zwei Morgen Weinberge samt den Leuten, Kurmedalen, Zinsen, Renten, Recliten und dem Hofgerichte, sowie dem Zehnten von den Weinbergen und Äckern, endlich in Kürrighoven 40 Morgen Ackerland').

Wurde der Abt wegen der grossen Schuldenlast der Abtei beständig von schweren Sorgen gequält, so musste er anch nocl! den Schmerz erleben, dass in dem Kloster Reichenstein, welches seit dem Jabre 1208 der Leitung Steinfelds unterstand ${ }^{2}$, höchst ärgerniserregende, nicht näher bekannte Vorgänge sich abspieltet. Nach vorangegangener Untersuchung liess der Erzbischof Friedrick in Jahre 1373 den Steinfelder Kanonikus Nikolans, welcher in Reichenstein Prior war, in Gegenwart des Abtes Gerhard gefangell nehmen und mit bewaffneter Begleitung zur Abbüssung seiner Strafe nach Köln bringen, entzog dem Kloster Steinfeld das Recit der Leitung und Beaufsichtigung und schickte alle drei Jahre einen Geistlichen aus dem Weltklerus zur Ausübung der Seelsorge nach Reichenstein, während er sich selbst die Oberaufsicht ïber das Kloster vorbehielt ${ }^{3}$.

Uberzeugt von der Aussichtslosigkeit seiner Bemühungen. den tiefen wirtschaftlichen Stand der Abtei zu bebeu, trat der Abt im Jahre 1380, ebenso wie seine drei letzten Vorgänger, frei. willig von seinem verantwortungsvollen Amte zurück ${ }^{4}$ ).

1) S. die Originalurkunde Nr. 66 im Düsseldorfer Staatsarchiv.

2) S. Annalen 95, S. $72 \mathrm{f}$.

3) S. M. S. P. Ernst, Histoire du Limbourg, Tome VI, Liège 1847. p. $171 \mathrm{sq}$. In dem Tochterkloster Dünwald schloss der Abt Gerhard am 1. und 12. Mai 1378 zwei Kaufverträge ab. S. das Pergamentkartular a. a. O. L 3 fol. 41 und L 4 fol. 41 b. Zeitschr. des Berg. Geschichts. vereins $22, \mathrm{~S}$. 136.

4) S. die Originalurkunde Nr. 67 im Düsseldorfer Staatsarchiv, ill der es heisst: Cum Steinveldensis ecclesia esset pastoris destituta solatio per domini Gerhardi de Heingin ultimi sui prelati liberam resigna. cion em. Gegen diese urkundlich gesicherte Nachricht können die aus der Uberlieferung geschöpften Berichte Hugos (Annales II, col. 858): Suspiria extrema trahentem abbatiam suffocasset male consultus abbrs, nisi rigor ordinis pessimum oeconomum judiciali sententia extru. disset anno 1380 und der Series praep. et abb. Steinf.: Ob malum regimen ab officio depositus est, zumal dieselben wahrscheinlich auf dieselbe Quelle zurückgehen, nicht standhalten. Gerhard lebte noch im Jahre 1399, über 60 Jahre alt. 


\section{Abt Gottfried ron Bonnenberg (1381-1388).}

Im Auftrage des Generalabtes von Prémontré beriefen der Alut Heinrich von Knechtsteden und der Propst Werner von Wenau an1 22. Januar 1381 alle Kanoniker des Steinfelder Stiftes zur IVahl eines neuen Abtes zusammen und richteten drei Tage später all den Erzbischof Friedrich von Köln schriftlich die Bitte, dem Neugewählten, dem bisherigen Steinfelder Chorherrn Gottfried rou Bonnenberg, das ihm zugefallene Amt zu übertragen ${ }^{1}$ ).

Um eine Schuld von 5000 Goldgulden bei den Gläubigern, welche mit Ungestüm auf Zahlung drängten, wenigstens zom Teil abtragen zu können, verkaufte der Abt in Verbindung mit seinem schat/meister Gerbard am 26. Januar 1387 nach eingehenden Beratungen und Verhandlungen in mehreren Kapitelssitzungen und mit Zustimmung des Erzbischofs Friedrich und des Kölner bomkapitels an den Propst der Kirche St. Severin zu Köln, Hupert Molghin, Lizentiaten des weltlich-römischen Rechtes ${ }^{2}$ ), für (60) Gulden die Höfe in dem Kirchspiel Kelz ${ }^{3}$ ) und der Ortschaft huirrighoven (in der Pfarre Bachem), beide mit allen zugehörigen liitern, wie Hofstätten, Häusern und sonstigen Gebäulichkeiten, bebautem und unbebautem Ackerland, Wäldern, Forsten, Weiden, VIicsen, Bächen, Wegen, unwegsamen Orten, Zehnten, Zinsen, Renten, Forderungen, Ehrenrechten und Lasten, ferner zwei Morgen Weinherge mit Waldungen bei Bornheim in der Pfarre Brenig.

Von dem zu dem Hofe in Kelz gehörigen Ackerland, welches 1\%. Mansus gross war, und den Wäldern, welche 20 Morgen umfassten, waren 30 Morgen Ländereien und 10 Morgen Wald,

1) S. die Originalurkunde Nr. 67 im Düsseldorfer Staatsarchiv und alie series praep. et abb. Steinf.

2) Jerselbe ist offenbar identisch mit dem gleichnamigen Dechanten dי. Kassiusstiftes in Bonn, von welchem der ehemalige Abt Winrich die vrrfiudeten Klostergüter in Fritzdorf, Benghoven und Kürrighoven :uf lobenszeit in Pacht genommen hatte. S. oben S. 79. Vermutlich war Winrich im Jahre 1387 gestorben, so dass diese Güter wieder frei "Worden waren und demgemäss vou neuem veräussert werden konnten.

3) Wenn oben (S. 77) berichtet wurde, dass schon der Abt Conrad d'n Iof in Kelz verkauft habe, so ist anzunehmen, dass dieser Kauf inawischen entweder rückgängig gemacht war oder erst jetzt die urkundliche Bestätigung durch den Erzbischof und das Domkapitel rhiclt.

Amialen des hist. Vereins XCVI. 
sowie einige Hofstätten der Äbtissin Margarethe des Quirinus. stiftes in Neuss ${ }^{1}$ ) zinspflichtig, 30 weitere Morgen Ländereien zahlten an das Ursulastift in Köln ${ }^{2}$ ); die tibrigen Morgen Acker. land und Wald waren ein Lehen der Äbtissin in Neuss, während die sonstigen Güter des Hofes als Allodialgut von allen Lasten und Pflichten frei waren. Die Güter in Kürrighoven, nämlich 44 Morgen Ackerland, sechs Morgen Wald und fünf Morgen Weiden. pflanzungen; waren für eine jäbrliche Rente von 14 Maltern Weizen an mebrere Laien verpachtet gewesen, da sie fur das Steinfelder Kloster ungünstig gelegen waren und nur geringen Ertrag ab. warfen. Die Weinberge in Bornheim aber, welche das Kloster unbebaut gelassen hatte, weil sie ertragsunfähig schienen, batte Hupert schon frühcr auf seine Kosten im Einverständis mit den Steinfelder Chorherren in guten Zustand gebracht ${ }^{3}$ ).

Vier Tage später (30. Jannar) gab der Propst Hupert die urkundliche Erklärung ab, dass die Abtei, welche ihm seit langer Zeit 2660 Goldgulden (und noch andere nicht genannte Summen. schuldete, zur Zeit aber nicht imstande war, in barem Gelde die ganze Schuld zurückzuzahlen, nach Leistung einer Teilzahlung ibm alle ihre Güter in Nörvenich mit sämtlichen Früchten, Rechten und Zubebör auf Lebenszeit verschrieben babe, mit der Befugnis, dass, wenn er im Besitze and Gennss dieser Güter oder in der lebenslänglichen Nutzniessung einer Summe von 150 Gulden oder im Genuss der in den Ortschaften Fritzdorf und Benghoven, Kelı, Kürrighoven und Bornbeim gelegenen Güter gestört würde, er auf Grund der ausgestellten Schuldbriefe gerichtlich gegen dir Störenfriede vorgeben könne.

Damit aber nach seinem Tode der Steinfelder Abtei durcli die Schuldbriefe keine Schwierigkeiten bereitet wirrden, bestimmte und verfügte er weiter, dass die übrigen Schuldbriefe, die ilum oder seinem verstorbenen Onkel Adam von Aldewyre vor dem

1) Uber die Äbtissin und die Besitzungen des Stiftes in Neuss : $\mathrm{K}$. Tücking, Geschichte der kirchlichen Eimrichtungen in der Stadt Neuss. Neuss 1890, S. 28.

2) Über Unregelmässigkeiten, welche damals auf wirtschaftlichell Gebiete im Stifte vorkamen und alsbald eine Teilung der Verwaltun: der Stiftsguiter zur Folge hatten, s. J. Zündorf, Zusammensetzung un Verfassung des Kölner St. Ursulastiftes, Bonn 1911, S. 46. 58.

3) S. die Originalurkunde Nr. 69 im Düsseldorfer Staatsarchir. 
Jahre 1383 ausgestellt waren, insbesondere der Schuldbrief über die genannten 2660 Goldgulden, nach seinem Tode null und nichtig seill sollten, so dass seine Erben oder Rechtsnachfolger gegen die Abtei keine Ansprüche zu erheben berechtigt waren. Ausserdem versprach er, dass er die Abtei auch zu seinen Lebzeiten auf (irund des Schuldbriefes von 2660 Goldgulden nicht belangen wiirle, wenn sie die in den anderen Schuldbriefen aufgestellten Bedingungen uber die ihm auf Lebenszeit zugesicherten Renten, Sutzmiessungen und anderen Güter, sowie tuher die Güter und iliren Ertrag in Fritzdorf und Benghoven und endlich über die ron ilm angekauften Höfe und Gïter in Kels, Bornheim und Kürrrighoven pünktlich erfüllen würde ${ }^{1}$ ).

Wie boch die finanzielle Not der Abtei inzwischen gestiegen war, zeigt der folgende bemerkenswerte Vorfall. Als während der Regierung des Abtes Gottfried - das Jahr ist unbekannt der Edellerr Gerhard VII. von Blankenheim, Herr zu Kastelburg ${ }^{2}$ ), leu Hof zu Ripsdorf und zahlreiche Kleinodien im Werte von i,u Mark als Erbrente für den Laurentiusaltar in der Pfarrkirche ..1 Steinfeld und der Schultheiss Gerhard Hoen von Goltbach und seilue Schwester Catharina in dem Amte von Sistich 100 rheinische linlten für drei Wochenmessen an dem Nikolausaltare in derselben hirche gestiftet hatten, wurden diese Güter nicht zu dem be: alsichtigten Zwecke, sondern zur Tilgung von Schulden verwandt, und für die Stiftungen der beiden Altäre erst unter dem Nach[n) grer Gottfrieds andere Einkünfte angewiesen ${ }^{3}$ ).

1) S. die Originalurkunde $\mathrm{Nr} .70$ ebendaselbst.

2) S. Schannat-Bärsch a. a. O. I, 1, S. 228 f. $266 \mathrm{ff}$.

3) S. die Originalurkunde $\mathrm{Nr} .81$ im Dässeldorfer Staatsarchiv. Ii- Ner Regierungstätigkeit des Abtes Gottfried ist nur noch zu erwihuen, dass er am 24. Juni 1384 den Weinberg zu Ediger an der Misel, genannt der Plentzer, an die Eheleute Hennen und Grete von ditrilu verpachtete (s. die Originalurkunde $\mathrm{Nr}, 68$ im Düsseldorfer Yitits:trchiv) und am 22. April 1388 sich gemeinsam mit dem Schatzmater Gerhard auf Grund eines Vertrages mit der Abtissin des freiweltbich'n Cücilienstiftes in Köln verpflichtete, diesem von der Mühle zu Ahrweiler, von welcher die Abtei jährlich zehn Malter Roggen bezog, "wie ron dem Hofe und den Gütern zu Losheim im Kreise Malmedy "Men jährlichen Zins von 48 alten Groschen zu zahlen. S. Bärsch a. a. O, $\therefore 36$ (ohne Angabe der Quelle). 
Der Abt selbst fand ein tragisches Ende. Eine Räuberbande, die unter dem Namen „Bretonen ${ }^{\text {o oder } ~}$ Englische“ bekannt und berüchtigt war $^{1}$ ) und von Valerianus, dem Bruder Peters von Luxemburg, geführt wurde, rückte gegen Steinfeld vor, nachdem sie die Trierer Diözese verwüstet hatte. Sie plünderte die Abtei vollständig aus und zerstörte die Gebäulichkeiten. Den Abt führte sie gefangen fort, in der Hoffnung, ein schweres Lösegeld für seine Freilassung zu erhalten. $\mathrm{Da}$ sie aber eine grössere Summe verlangte, als man ihr geben konnte, tötete sie den Schwergepruften nuit barbarischer Grausamkeit am 17. Dezember $1388^{2}$ ).

\section{Abt Gerhard II. von Wichterich (1389-1412).}

Mit der Ermordung des Abtes Gottfried und der Zerstörung der Gebäulichkeiten hatte das Unglück, welches seit der Mitte des 14. Jahrbunderts über die Abtei hereingebrochen war, seinen Höhepunkt erreicht. Der im Anfange des Jahres 1389 neu gewählte Abt Gerhard, welcher im Jahre 1374 Prior in Meer ${ }^{3}$ ) und 1387 und später Schat\%meister in Steinfeld ${ }^{4}$ ) gewesen war, ergriff sofort mit starker Hand die Zügel der Verwaltung, um wieder wirtschaftlich gesunde und geordnete Zustände in Steinfeld herzustellen.

Nachdem er am 22. Juni 1390 den Hof zu Ellenz an der Mosel mit Weingärten, Lehensleuten und Zinsen an die Eheleute Hennen und Grete von Adenau verpachtet hatte ${ }^{5}$ ), dieselben, welche früher auch den Weinberg zu Ediger an der Mosel von der Abtei in Pacht genommen hatten ${ }^{6}$ ), gab er ihn am 5. November 1404 gegen ein Drittel der jährlichen Weinerträge von

1) S. F. Ferdinand, Cuno von Falkenstein als Erzbischof von Trier, Coadjutor und Administrator von Köln, Paderborn 1885, S. $34 \mathrm{f}$.

2) S. Hugo, Annales II, col. 858.

3) S. H. Keussen, Das adelige Frauenkloster Meer bei Neuss, Crefeld 1866, S. 53.

4) S. oben S. 81 und 83, Anm. 3.

5) S. die Originalurkunde Nr. 71 im Düsseldorfer Staatsarchiv. Es ist anzunehmen, dass Hille von Dunebach, welche diesen Hof zu Ellenz auf Lebenszeit übernommen hatte, inzwischen gestorben war. S. oben S. 78, Anm. 2 .

6) S. oben S. 83 , Anm. 3 . 
n'tuem an Heinrich Wilhelms und eines seiner Kinder aus erster Whe mit seiner Frau Elsgin in Pacht ${ }^{1}$ ). Am 20. März 1405 verparchtete er mit seinem Prior Arnold an die Eheleute Henkin unll Gertrud Schürmann in Lengsdorf gegen eine jährliche Rente roll einer Tonne Wein mitsamt dem Fass und zwei Schillingen den in Lengsdorf gelegenen Weinberg von einem halben Morgen ${ }^{2}$ ), welchen der Steinfelder Kanonikus Hermann von Bonn der Abtei 1359 testamentarisch vermacht hatte ${ }^{3}$ ). Als er den Bürger Vicchael Becker in Zülpich wegen der rückständigen Pacht von vier. Horgen Ackerland, die in Zülpich (in der vidtzschen up dem urvenen wege) gelegen waren, gerichtlich belangt hatte, erklärte dicser am 20. Mai 1411 urkundlich, dass er und seine Erben jialrlich am 1. Oktober als Erbpacht drei Sümmer ${ }^{5}$ ) Roggen an das Steinfelder Kloster abliefern würden ${ }^{5}$ ).

Weiter erreichte der AbtGerhard zugunsten seines Klosters, dass der Vogt \%u Münstereifel, Johann Elreborn, und seine Frau Grete, welchen er für ein Darlehen von 700 Gulden bzw. 70 Gulden /iusen verschiedene Unterpfänder mit der Bedingung gestellt hatte, dass diese den Gläubigern verfallen sein sollten, wenn die Zinsen rückständig blieben, am 18. August 1401 diese Bedingung aufhuben und sich mit einer allgemeinen Hypothek auf das gesamte abteiliche Vermögen begnügten, gleichviel in welchem Lande und Gerichte dasselbe gelegen war ${ }^{6}$ ). Und am 1. Februar 1402 yel:mır es ihm, die Mühle, die Pächte, Zinsen und sonstigen Güter les K'losters zu Lindweiler ${ }^{7}$ ) im Kreise Schleiden, welche der Frau lisa von Droeve in $\operatorname{Rohr}^{8}$ ) und ihren Kindern (umb eyne summa ran gelde) verpfändet waren, wieder einzulösen ${ }^{9}$ ).

1) S. die Originalurkunde Nr. 78 im Düsseldorfer Staatsarchiv.

2) S. die Originalurkunde $\mathrm{Nr}$. 79 ebendaselbst.

3) S. oben S. 75 .

4) 4 Sümmer gingen auf einen Malter. S. Ennen a. a. O. I, S. 504.

5) S. die Originalurkunde im Stadtarchiv zu Köln. Mitt. a. d. Stadtarehiv 16, S. 42.

6) S. die Originalurkunde Nr. 75 im Düsseldorfer Staatsarchiv.

7) S. Annalen 95, S. 77.

8) Die Besitzung in Lindweiler gehörte zu dem Kirchspiel Rohr. S labricius a. a. O. S. 168 .

9) S. die Originalurkunde Nr. 77 im Düsseldorfer Staatsarchiv. Am $\because$ Frbruar 1403 erklärten Paitza von Ejmich, die Witwe des Ritters Inhmn von Kleberg, und die Ritter Heinrich von Dadenberg, Johann von Breydemar und Johann Scheyffart vanme Roede urkundlich, dass 
Ausserdem flossen der Abtei bei verschiedenen Anlässen seitens begüterter Wohltäter Schenkungen und Stiftungen zu, welche dazu beitrugen, der herrschenden Not.zu steuem. $S_{i,}$ erhielt der Abt Gerhard am 19. April 1393 von der Familic Zeuwelgin in Köln, nämlich Arnold ${ }^{1}$ ), seiner Schwester Adelheid und deren Gemahl Gottfried von Dovere, als Mitgift für ihrell Neffen Heinrich, den Sohn des verstorbenen Bürgers Heinrich Bollaerts und seiner Frau Gertrud Zeuwelgin, welcher ins Kloster Steinfeld eingetreten war ${ }^{2}$ ), das Haus Steinfeld in Köln in der Enggasse (Sporergasse) bei dem Erbe Scheichterstein im Kirchspiel St. Laurentius ${ }^{3}$ ), in welchem sich fünf Wohnungen befanden. und aus welchem die Abtei eine jährliche Rente von 20 Guldeu an die Jungfrau Elise von Eiggener (van den Egher) und eine solche von zehn Gulden an den Konvent St. Klara in Köln, in welchem Elise Nonne war, zu entrichten hatte, ferner das halbe

sie ron dem Hofe zu Losheim, welchen der Ritter Johann von Kleberr und seine Frau Paitza von dem Kloster Steinfeld gekauft hatten, diesell ursprünglich eine Erbrente von einer Mark schuldig waren und in dessell Auftrage am 1. Oktober an das Cäcilienstift in Köln zu entrichten hatten. (Vgl. oben S. 83, Anm. 3.) Später aber übertrugen sie diese Rente auf andere Güter des Klosters und mussten fortan am 29. August (Johannis decollacio) an den Pastor der Martinspfarre in Zülpich, der regelmässi: ein Steinfelder Kanonikus war, statt der einen Mark 4 Gulden zahle!! Die Schöffen zu Losheirn, die als Zeugen bei der Abschliessung des Vir trages zugegen waren, erhielten die Anweisung, im Falle einer Zahlung.. versäumnis das Kloster Steinfeld in den Besitz der Unterpfänder zn setzen, welche die Käufer gestellt hatten. S. die Originalurkunde inr Stadtarchiv zu Köln. Mitt. a. d. Stadtarchiv 14, S. 19. Herr Archivar Professor Dr. Keussen hatte die Güte, mir den Inhalt der Urkunde aus. zuschreiben. Ich unterlasse nicht, ihm hierfür herzlich Dank zu sagen

1) S. Keussen, Topographie I, S. 163a, 1.

2) Am 22. März 1401 gab ihm der Abt Gerhard die Erlaubnis, daHaus zum Pallas auf der Breitestrasse mit dem dahinter gelegenen Hotr Hüchelhoven an die Kölner Bürger und Eheleute Arnold und Catharin: von Caldenberg zu verkaufen, um sich eine Leibzuchtsrente zu sichern S. die Originalurkunde Nr. 881 im Stadtarchiv zu Köln. In dieser Urkund. wird der Steinfelder Chorherr Heinrich als Sohn des verstorbenen Heinric! von Hinteren und der Gertrud Zeuwelgin bezeichnet, während er in de: Urkunde vom 19. April 1393 als Sohn des verstorbenen Heinrich Bollaerund der Gertrud Zeuwelgin erscheint. Uber das Haus zum Pallas : Keussen, Topographie I, S. 282, 16-19. 290 b, 2. 3. 4; über Annold vol Caldenberg s. ebenda S. 284, b. 14. 15. 290 b, 4-6.

3) S. ebenda S. 218 , a, 1. 2. 
Hatls Geveross im Kirchspiel St. Laurentius ${ }^{1}$ ), aus dem die Abtei eille jährliche Rente von $10^{1} / 2$ Gulden an Johann vom Hirze unl eine solche von sechs Gulden an Elise Bollartz, die Schwester des genannten Heinrich, die in St. Agatha Nonne war, zahlen musste, endlich drei Viertel Weingarten zu [Ober-?] Cassel, die unbelastet waren ${ }^{2}$ ). Als die Nonne Elise gestorben war, verzichtete die Ihtissin des Klaraklosters, Rykinde von Alfter, am 13. März 1409 urktudlich auf die genannten Einkünfte und übergab zugleich dem Abte Gerhard 50 rbeinische Gulden, auf die er vertraglich in dell drei ersten Jahren nach dem Tode der Nonne Anspruch latate ${ }^{3}$.

Am 8. April 1412 empfing der Abt von den Ehegatten Peter und Ailken von Aiche 15 rlieinische Gulden, von ibrem subne Dietrich, der in Münstereifel Kanonikus war, acht Gulden, rom ilurem Sohne Johann Elreborn und dessen Frau Grete eine jialrliche Erbrente von einem Malter Spelt, die von ihrem Hofe in liauwe zu liefern waren, von Peter Elreborn und dessen Frau Lilsgyn zehn Gulden und von Johann Ardorp und dessen Frau Nertelen, ibrer Tochter, zebn Gulden. Für diese Summe kaufte ar eine Rente von secbs Maltern Spelt, welche unter die Mitglieder des Konventes an den beiden Tagen verteilt wurde, an welchen '‘ul Gedächtnis mit Messe, Kommendation und Vigilien für die sififter im Kloster gehalten werden musste, nämlich an den ersten Yontagen nach dem Feste des hl. Martinus und nach Halbfasten ${ }^{4}$ ).

Auch das religiös-kirchliche Leben nahm unter dem Abte lierhard einen neuen Aufschwung. Der Ritter Heinrich von Hüchelluren, Erbschultheiss zu Escbweiler, stiftete am 2. Mai 1398 in firmeinschaft mit seiner Frau Margaretha zum Heile seiner versturbenen Eltern und Verwandten, insbesondere des Pastors Reynard roll Adendorf, seines Onkels, des Ritters Wilhelm von Bonnen unil seiner Frau Gertrud, seines Schwagers und seiner Schwägerin,

1) S. ebenda S. 205, a, 1-6; b, 6. 7 .

2) S. die Originalurkunde Nr. 72 im Düsseldorfer Staatsarchiv.

i) S. die Originalurkunde $\mathrm{Nr}$. 80 ebendaselbst.

4) S. die Originalurkunde Nr. 82 ebendaselbst, welche von den l'rimonstratenseräbten Johann Hasart von Knechtsteden und Constantin wn Hamborn mitunterzeichnet ist, und von den Steinfelder Chorherren allilrïcklich den Prior Johann und den custos (Pfarrer) Jakob erwähnt. 
eine Kapelle in Arzdorf ${ }^{1}$ ) in dem Kirchspiel Fritzdorf und dotierte sie mit einer jährlichen Rente von 25 Mark. Der Abt von Stein. feld gab dieser Stiftung seine Genehmigung und der Pastor Arnold von Neichtersheim in Fritzdorf übernahm für sich und seine Nachfolger die Verpflichtung, in der Kapelle jeden Dienstag oder all einem andern Wochentage eine heilige Messe entweder selbst zu lesen oder durch einen andern geeigneten Geistlichen lesen zu lassen. Dafür erhielt er das Recht, alle Gaben, welche dic Gläubigen in der Kapelle opferten, für sich zu behalten, musste aber andererseits sich damit einverstanden erk]ären, dass ihm für jede nicht gehaltene Messe sechs Schillinge ron der Rente al). gezogen wurden ${ }^{2}$ ). Als in der Pfarre Reifferscheid, welche im Jahre 1130 errichtet und unter die Leitung Steinfelds gestellt war $\left.^{3}\right)$, der Pastor Wilhelm Vlann das Zeitliche gesegnet hatte. richtete der Edelherr Johanu von Reifferscheid, Bedburg und Diek ${ }^{4}$ ), am 5. November 1401 an den Abt, der über die Pfarre Archidiakonalrechte ausübte ${ }^{5}$ ), die Bitte, er möge das erledigtc Amt, dessen Besetzung ihm als den Grundherrn kraft des Patronatsrechts (pleno jure) zustand, dem von ihm präsentierten Kleriker Johannes vou Swahnen aus der Kölner Erzdiözese übertragelı und ihn unter den ibblichen Feierlichkeiten in den Besitz des Amtes und den Genuss der Einkünfte einführen ${ }^{6}$ ).

Um die unter seinem Vorgänger Gottfried gemachten Stiftungell des Edelherrn Gerhard von Blankenheim, welcher inzwischen gestorben und in der Abteikirche beerdigt war, und des Schult. heissen Gerhard Hoen, deren Erträgnisse zur Tilgung von Schuldeu verwandt worden waren ${ }^{7}$ ), im Sinne der Stifter in rechtmässigei

1) Dieselbe wurde geweiht zu Ehren der Gottesmutter und de: Heiligen Stanislaus, Antonius und Servatius.

2) S. Annalen 24, S. 295 ff. Mitt. a. d. Stadtarchiv 12, S. 16. Fïm Kopie der Urkunde (aus dem 17. Jahrhundert) findet sich in den Farra gines Gelenii VIII, S. 263 ff. (Handschrift auf dem Stadtarchiv zu Kölı

3) S. Annalen $93, \mathrm{~S} .26 \mathrm{f}$.

4) S. Schannat-Bärsch a. a. O. I, 2, S. 625 ff. 924 .

5) S. Fabricius a. a. O. S. $174 \mathrm{f}$.

6) S. die Originalurkunde Nr. 76 im Düsseldorfer Staatsarchis Über das Recht der Archidiakone, die Pfarrer zu investieren, s. Hall: a. a. O. V, 1. S. $224 \mathrm{f}$.

7) S. oben S. 83 . 
Weise sicherzustellen, überwies er am 8. April 1412 dem Laurentiusand dem Nikolausaltare in der Pfarrkirche zu Steinfeld die Gefalle eines Gutes zu Langendorf ${ }^{1}$ ) bei Zülpich, welches er wieder cingelöst hatte, sowie des Hofes zu Ripsdorf und ausserdem drei ohm Wein aus dem Weinzebnten zu Benghoven. Zugleich ordnete er an, dass abwechselnd die Priester des Konventes für die Seelenrulle des Herrn von Blankenheim und seiner verstorbenen Verwandten eine Woche lang täglich ein Hochamt an dem Hochaltare, in der folgenden Woche täglich die Frühmesse auf dem neuen lltar \%wischen dem Laurentius- und Nikolausaltar und in der dritten Woche Montags, Mittwochs und Freitags eine Messe an dem Laurentinsaltare lesen sollten, während sie Dienstags, Donnerstags und Samstags an dem Nikolausaltare eine Messe für den Stifter (ierhard Hoen, seine Fran Gertrud und seine Schwester Catharina an lesen hatten. Dafür erhielt jeder Priester nach Ablanf der dritten Woche vom Prior oder Pitanzier zwölf Quarten Wein; was an Korn, Hafer, Wein und Geld übrig blieb, wurde zu rleichen Teilen unter die Priester verteilt ${ }^{2}$ ).

18 Tage nach Erledigung dieser Angelegenheit (26. A pril 1412) schied der Abt Gerhard aus dem Leben ${ }^{3}$ ), nachdem er mebr als 23) Jahre der Steinfelder Abtei vorgestanden hatte. Wenn die series praep. et abb. Steinf. von ihm sagt: Quamvis plurimos hahbuerit suo tempore adversarios . . o omnes patienter et fortiter sustinuit, so ist wohl zu bedenken, dass ein Manu, der eine so yrosse und schwierige Aufgabe zu lösen hatte, wie dieser Abt, selir leicht auf Widerstand und Gegner stossen konnte oder gar

1) S. oben S. 64 .

2) S. die Originalurkunde Nr. 81 im Düsseldorfer Staatsarchiv, welche ebenso wie die oben S. 87 erwähnte Urkunde von demselben Datum von den Prämonstratenseräbten Johann Hasart von Knechtsteden und Constantin von Hamborn untersehrieben und besiegelt ist und Alsserdem die Unterschriften von 16 Prämonstratenserchorherren träg't, niimlich: Pastor Jakob in Fritzdorf, Propst Wanne (?) in Heinsberg, lohames Wynrich in Steinfeld, Prior Arnold in Dünwald, Johannes Büschelmann in Meer, Peter in Reichenstein, Prior Philips in Hochkirchen, Christian in Benghoven, Johann in Schleiden, Wilhelm in Notlerer, Christian in Zülpich, Johann in Ripsdorf, Pastor Jakob, Pastor Jhann von Bonn, ehemaliger Weinmeister Walter von Urdingen und Johann von Adenau.

3) S. Bärsch a. a. O. S. 15. 
musste, wofern er sein Ziel, die Wiederherstellung der fast unter. gegangenen Abtei ${ }^{1}$ ), beharrlich im Auge behielt und mit allen ibm zur Verfügung stehenden Mitteln tatkräftig verfolgte.

Aber dieselbe series muss ihm das rühmliche Zeugnis aus. stellen: Relevavit monasterium, plurima bona divendita et obligata redemit et petrae rursus copulavit ita, ut quasi secundus fundator exstitisse scribatur. Und so gebührt ihm das weitere unbestreitbare Verdienst, eine neue Blüteperiode für die Abtei Steinfeld eingeleitet $z$ uaben.

1) Dazu kamen nocb die Sorgen und Bemühungen um das verschuldete Tochterkloster Dünwald: Ab hac [der Meisterin Wilhelma vou Obbendorf] Gerhardus abbas Steinfeldensis anno 1406 computum ex. cepit et ob debitum, quo in pecuniis 2683 dalerorum obstrictum erat monasterium, ad meliorem statum illud conatus est reducere. S. Annalen 44, S. 114 . 